\title{
Comparative analysis of inbreeding parameters and runs of homozygosity islands in 2 Italian autochthonous cattle breeds mainly raised in the Parmigiano-Reggiano cheese production region
}

\author{
Giuseppina Schiavo, ${ }^{1} \odot$ Samuele Bovo, ${ }^{1} \odot$ Anisa Ribani, ${ }^{1}$ Giulia Moscatelli, ${ }^{1}$ Massimo Bonacini, ${ }^{2}$ \\ Marco Prandi, ${ }^{2}$ Enrico Mancin, ${ }^{3}$ Roberto Mantovani, ${ }^{3}$ Stefania Dall'Olio, ${ }^{1}$ and Luca Fontanesi ${ }^{1 *}$ \\ ${ }^{1}$ Department of Agricultural and Food Sciences, Division of Animal Sciences, University of Bologna, Viale Giuseppe Fanin 46, 40127 Bologna, \\ Italy \\ ${ }^{2}$ Associazione Nazionale Allevatori Bovini di Razza Reggiana (ANABORARE), Via Masaccio 11, 42124 Reggio Emilia, Italy \\ ${ }^{3}$ Department of Agronomy, Food, Natural Resources, Animals and Environment (DAFNAE), University of Padova, Viale dell'Università 16, \\ 35020 Legnaro (PD), Italy
}

\section{ABSTRACT}

Reggiana and Modenese are autochthonous cattle breeds, reared in the North of Italy, that can be mainly distinguished for their standard coat color (Reggiana is red, whereas Modenese is white with some pale gray shades). Almost all milk produced by these breeds is transformed into 2 mono-breed branded ParmigianoReggiano cheeses, from which farmers receive the economic incomes needed for the sustainable conservation of these animal genetic resources. After the setting up of their herd books in 1960s, these breeds experienced a strong reduction in the population size that was subsequently reverted starting in the 1990s (Reggiana) or more recently (Modenese) reaching at present a total of about 2,800 and 500 registered cows, respectively. Due to the small population size of these breeds, inbreeding is a very important cause of concern for their conservation programs. Inbreeding is traditionally estimated using pedigree data, which are summarized in an inbreeding coefficient calculated at the individual level $\left(F_{\mathrm{PED}}\right)$. However, incompleteness of pedigree information and registration errors can affect the effectiveness of conservation strategies. High-throughput SNP genotyping platforms allow investigation of inbreeding using genome information that can overcome the limits of pedigree data. Several approaches have been proposed to estimate genomic inbreeding, with the use of runs of homozygosity ( $\mathrm{ROH})$ considered to be the more appropriate. In this study, several pedigree and genomic inbreeding parameters, calculated using the whole herd book populations or considering genotyping information (GeneSeek GGP Bovine 150K) from 1,684 Reggiana cattle and 323 Modenese cattle, were com-

Received June 24, 2021.

Accepted October 25, 2021.

*Corresponding author: luca.fontanesi@unibo.it pared. Average inbreeding values per year were used to calculate effective population size. Reggiana breed had generally lower genomic inbreeding values than Modenese breed. The low correlation between pedigree-based and genomic-based parameters (ranging from 0.187 to 0.195 and 0.319 to 0.323 in the Reggiana and Modenese breeds, respectively) reflected the common problems of local populations in which pedigree records are not complete. The high proportion of short $\mathrm{ROH}$ over the total number of $\mathrm{ROH}$ indicates no major recent inbreeding events in both breeds. $\mathrm{ROH}$ islands spread over the genome of the 2 breeds (15 in Reggiana and 14 in Modenese) identified several signatures of selection. Some of these included genes affecting milk production traits, stature, body conformation traits (with a main $\mathrm{ROH}$ island in both breeds on BTA6 containing the $A B C G 2, N C A P G$, and $L C O R L$ genes) and coat color (on BTA13 in Modenese containing the ASIP gene). In conclusion, this work provides an extensive comparative analysis of pedigree and genomic inbreeding parameters and relevant genomic information that will be useful in the conservation strategies of these 2 iconic local cattle breeds.

Key words: $A S I P$, conservation genetics, effective population size, local breed, signature of selection

\section{INTRODUCTION}

Reggiana and Modenese are 2 autochthonous cattle breeds mainly reared in the 2 close provinces of Reggio Emilia and Modena (from which they took their names, respectively), that are in the Emilia-Romagna region, located in northern Italy. Geographically, these provinces are within the area of production of the well-known Protected Designation of Origin (PDO) Parmigiano-Reggiano cheese. Reggiana and Modenese are historically considered as part of the original cattle populations and dairy production system from which 
this cheese has been originated. Animals of these populations were the most frequent bovines in this area over the first half of the last century when they were considered triple-purpose cattle (dairy-beef-work). Nowadays, all milk produced by Reggiana and a large amount of milk produced by Modenese cattle is transformed into 2 mono-breed branded Parmigiano-Reggiano cheeses. The Reggiana mono-breed cheese was first constituted in 1991. As this cheese could be marketed at a higher price than the undifferentiated Parmigiano-Reggiano cheese, breeding Reggiana cattle became economically profitable despite the lower milk production of the Reggiana cows as compared with that of cows of cosmopolitan breeds (Gandini et al., 2007; Fontanesi, 2009). Since then, Reggiana population size reverted the general progressive decreasing trend that was experienced over the 1960s to 1980s (when it reached a minimum peak of about 500 cows). In 2020, this breed accounted a total of about 2,800 cows raised in about 100 farms. The National Association of Reggiana Cattle Breeders (ANABORARE), constituted in 1962, officially manages the Reggiana Herd Book. In 2020, ANABORARE became also in charge to the Modenese Herd Book, following a national reorganization program for the management of Italian cattle genetic resources (ANABORARE, 2020). The Modenese Herd Book was first recognized in 1957. The negative population size trend in Modenese has been similar to that of the Reggiana cattle since the 1960s, with a progressive fast reduction and a subsequent slow recovery that in the Modenese breed started later. In 2005, when a recovery program based on a mono-breed Parmigiano-Reggiano cheese was established, fewer than 260 cows were registered to the herd book that in 2020 accounted about 500 cows reared in 60 farms.

Reggiana and Modenese can be distinguished for their standard coat color: Reggiana cattle have a classical red coat color, indicated by the term "fromentino," over the whole body, with pink or pale muzzle color; Modenese cattle have a white coat on the body with some pale gray shades, a feature that provided a second name to this breed, Bianca Val Padana (bianca = white; Val Padana $=$ name of the Po river valley), with a muzzle that is, in part, black.

Inbreeding is an important parameter to monitor and control in animal genetic resources conservation programs. This is particularly relevant in autochthonous breeds that are usually small populations that have few unrelated animals. This situation usually determines a very low effective population size, which, in turn, causes a high inbreeding rate (Charlesworth and Willis, 2009). The consequence is usually a decline in performance and fitness of the population, defined with the general concept of inbreeding depression (e.g., Smith et al., 1998; Kristensen and Sørensen, 2005). The derived reduction of genetic variability is accompanied with an increased frequency of recessive and deleterious alleles with small to large effects in the populations, with negative effects on the selection potential and reproduction performances, that hampers the conservation of local breeds (e.g., Meuwissen, 1991; Fernández et al., 2002).

Inbreeding is traditionally estimated using pedigree data, which are summarized in an inbreeding coefficient calculated at the individual level $\left(\boldsymbol{F}_{\mathbf{P E D}}\right.$; Falconer and Mackay, 1996). In a diploid organism, $F_{\mathrm{PED}}$ is defined as the probability that, in a base population with different alleles, the 2 alleles at a randomly selected locus that are inherited from the paternal and maternal sides are identical by descent (Wright, 1922). That means that these alleles are originated from the same ancestral common individual that is shared by both the paternal and maternal lineages. This measure can be also defined as the proportion of autozygosity of an individual's genome. When a population is considered, the inbreeding is expressed as the average of the $F_{\mathrm{PED}}$ of all individuals that constitute the population.

The 2 general assumptions that are needed to calculate $F_{\mathrm{PED}}$ values at both the individual and population levels are that pedigree information is complete and all records are correct. Another important assumption that has to be considered in inbreeding estimation is that the base population of a pedigree is unrelated. These conditions do not completely hold in practice, particularly in livestock breeds raised in extensive or semi-extensive production systems where it is difficult to control all mating events and where a low professional management increases the error rate of the recording. A high misidentification rate that creates pedigree errors has been even reported in cosmopolitan cattle populations in intensive production systems, where recording is expected to be more precise than in other breeds or conditions (Ron et al., 1996; Visscher et al., 2002; Weller et al., 2004; Russo et al., 2012). The negative effects of the incompleteness of pedigree information or the detrimental effect of registration errors on the genetic progress and on the effectiveness of the conservation strategies of livestock populations have been clearly demonstrated (Banos et al., 2001; Visscher et al., 2002; Sanders et al., 2006; Oliehoek and Bijma, 2009; Reverter et al., 2016).

Commercial platforms for high-throughput genotyping available in many livestock species including cattle investigate thousands of SNP covering the whole genome. This genotyping information can be used to obtain more accurate estimates of realized inbreeding, obtaining genome-based measures. Genomic inbreeding parameters can overcome the problems caused by pedigree incompleteness, parentage errors, and the intrinsic 
limits of pedigree-based measures that are only expectations of the realized inbreeding coefficients, which do not take into account (1) the relatedness of the base populations, (2) the stochasticity of the recombination events occurring during meiosis, and (3) the potential biases derived by the selection on some genomic regions (Leutenegger et al., 2003; VanRaden, 2007, 2008; Hill and Weir, 2011; Wang, 2016; Howard et. al, 2017; Knief et al., 2017). Several approaches have been proposed to estimate the genomic inbreeding level: (1) a marker-bymarker evaluation of the level of heterozygosity across the genome, known as multilocus heterozygosity (e.g., Slate et al., 2004); (2) a method based on identity by state that summarizes SNP-by-SNP this information using a genomic relationship matrix (GRM; VanRaden et al., 2011); (3) methods based on runs of homozygosity $(\mathbf{R O H})$, which are continuous genomic regions presenting a homozygous genotype at each locus (Gibson et al., 2006; McQuillan et al., 2008). Some studies reported the correlation between pedigree and genomic inbreeding parameters in cattle breeds with contrasting results that could be attributed to the different population structures, the completeness of the pedigree information, the size of the population, and the variety of methods used to estimate genomic inbreeding coefficients (Ferenčaković et al., 2013a,b; Pryce et al., 2014; Marras et al., 2015; Zhang et al., 2015; Gurgul et al., 2016; Signer-Hasler et al., 2017; Peripolli et al., 2018a; Sumreddee et al., 2019; Alemu et al., 2021).

The computation of $\mathrm{ROH}$ can also give information on the genetic history of the populations (Keller et al., 2011; Ceballos et al., 2018). For example, the average length of all $\mathrm{ROH}$ of an individual and the genome coverage of $\mathrm{ROH}$ are indicators of the occurrence of inbreeding events and whether these events were recent (in case of long $\mathrm{ROH}$ ) or remote (short $\mathrm{ROH}$ ), because many recombination events can disrupt the recent long $\mathrm{ROH}$ inherited from common ancestors (Ceballos et al., 2018). The accumulation of ROH in some genome regions, indicated as $\mathrm{ROH}$ island or $\mathrm{ROH}$ hotspots, can be due to natural or artificial directional selection at certain loci, which reduce genetic variability at these regions, leaving signatures of selections particularly useful for the identification of variants affecting economically relevant and breed-specific traits (Mastrangelo et al., 2016; Bertolini et al., 2018; Schiavo et al., 2020a, 2021a).

Preliminary analyses of genomic inbreeding measures and on the distribution of $\mathrm{ROH}$ in the genome of Reggiana and Modenese breeds have been already reported using genotyping information from a few animals. In these studies, Reggiana showed a lower level of genomic inbreeding compared with Modenese, and both breeds showed an overall value that was lower than that of several other autochthonous cattle breeds. (Mastrangelo et al., 2016, 2018a). However, no comparative evaluation between pedigree and genomic-based inbreeding parameters have been obtained so far in these breeds. In addition, no retrospective analyses on the effects of the inbreeding rate and genetic diversity have been carried in these 2 breeds following the establishment of the conservation and selection programs that started in 1991 for the Reggiana breed and of the conservation strategy that subsequently initiated in 2005 for the Modenese breed. The Reggiana program was aimed to control the inbreeding rate and at the same time to maximize the production of milk for ParmigianoReggiano cheese through a purposely designed genetic index.

The objective of this study was to assess and compare different pedigree and genomic inbreeding parameters, for the first time in Reggiana and Modenese cattle breeds. These parameters were estimated by several approaches, taking advantage from genotyping information obtained from about two-thirds of the cattle populations of both breeds. Moreover, $\mathrm{ROH}$ islands were analyzed and compared in Reggiana and Modenese cattle to identify signatures of selection that could characterize and differentiate these 2 close autochthonous breeds and that might be also useful to explain genetic mechanisms affecting morphological and economically relevant traits in cattle.

\section{MATERIALS AND METHODS}

\section{Pedigree and Genotyping Data Sets}

Pedigree data available from the Reggiana and Modenese Herd Books accounted for a total of 47,551 and 10,975 records starting in the years 1951 and 1943, respectively. Details of the 2 breed populations, the characterization of their pedigree data sets (calculated with the software ENDOG v4.8; Gutiérrez and Goyache, 2005), and the evolution of knowledge of pedigree information over the years are shown in Table 1 and Figure 1, respectively. The herd book for these breeds includes some animals whose relatives are uncertain, if they reflect the standards of the breed. However, only males whose parents and grandparents have an assessed ascendance can be used for artificial or natural insemination. Pedigree parameters calculated were the number of fully traced generations per individual; the maximum number of generations traced, which are those separating the offspring of the furthest generation where the ancestors of the individual are known (ancestors with no known parents are considered as founders: 
Table 1. Number of genotyped individuals, number of SNP markers retained after filtering, records available in full pedigree and subpedigree data sets, equivalent number of complete generations of full genealogy, and generation interval (years) of full genealogy for the 2 cattle breeds

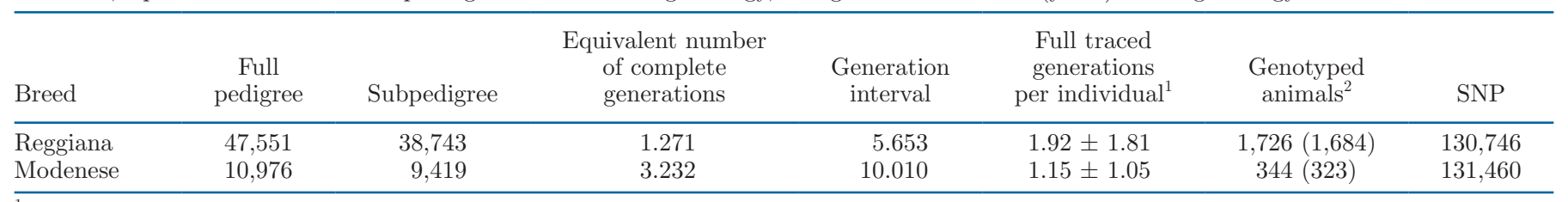

${ }^{1}$ Average value \pm SD for the full pedigree.

${ }^{2}$ Number of genotyped animals before and after filtering (in parentheses) applied as described in the text.

generation 0); the equivalent complete generations for each animal in the pedigree data set, computed as the sum over all known ancestors of the terms computed as the sum of $(1 / 2) n$, where $n$ is the number of generations separating the individual to each known ancestor (Maignel et al., 1996). The distribution of the complete generation equivalence is reported in Supplemental Figure S1 (https://doi.org/10.5281/zenodo.5532620; Schiavo et al., 2021b).

A total of 1,726 Reggiana cattle and 344 Modenese cattle were genotyped with the GGP Bovine150K (Neogen) according to the producer's protocols. Animals were not treated in any way, and they were raised according to national and European legislation. Sampling operations were carried out under routine veterinary inspections, thus no ethical permit was needed. Genotyped Reggiana and Modenese animals were sampled among primiparous or multiparous females and a few males (35 for Reggiana and 2 for Modenese) born between 2000 and 2018 and between 2005 and 2018, respectively. The SNP were mapped on the ARSUCD1.2 assembly of the Bos taurus genome. Only SNP located in unique positions and mapped on autosomal chromosomes were retained. Quality check and filtering steps were performed with PLINK v1.9 (Chang et al., 2015): animals with call rate $>0.90$ were retained; SNP were discarded when the call rate was $<0.90$ or $P$ in Hardy-Weinberg equilibrium analysis was $<0.0001$. The SNP were not filtered for minor allele frequency as this exclusion could bring to an underestimation of the coverage of ROH (Meyermans et al., 2020). After the filtering step, the remaining number of animals was 1,684 for Reggiana and 323 for Modenese. The remaining SNPs were 130,746 for Reggiana and 131,460 for Modenese.

Among the remaining genotyped animals, pedigree information was matched for 1,594 and 321 cattle in Reggiana and Modenese breeds, respectively. The minimum depth of generations for the pedigree records in these animals ranged from 0 to 6 . Genomic inbreeding analyses were performed on the whole cleaned data set as described below.

\section{Inbreeding Parameters}

Inbreeding coefficients based on pedigree information $\left(F_{\mathrm{PED}}\right)$ were calculated with 2 different methods with software Inbupgf90 (Aguilar and Misztal, 2008): $\boldsymbol{F}_{\text {PEDW }}$ was estimated according to Wright's coefficient (Wright, 1922) with the algorithm proposed by Meuwissen and Luo (1992); $\boldsymbol{F}_{\text {PEDR }}$ was computed with the recursive method proposed by VanRaden (1992) and implemented in Inbupgf90, where the inbreeding of the animals with unknown parents was estimated based on the mean of the inbreeding coefficients of the other animals that were born in the same year, using 30 iterations. Average relatedness ( $\mathbf{A R}$, indicated here as $\boldsymbol{F}_{\mathrm{AR}}$; Goyache et al., 2003; Gutiérrez et al., 2003) was calculated on pedigree information using ENDOG v4.8. The AR is defined as the probability that an allele randomly chosen from the whole population in the pedigree belongs to a given animal, used as a measure of inbreeding of the population, as it accounts both inbreeding and coancestry coefficients (Goyache et al., 2003; Gutiérrez et al., 2003). Kalinowski ancestral pedigree inbreeding was calculated using GRAIN (Baumung et al., 2015), as reported by Makanjuola et al. (2020).

Genomic inbreeding level was estimated with several methods that used genotyping information. The $\mathrm{ROH}$ were computed with PLINK 1.9 according to previous works (Ferenčaković et al., 2013a,b; Marras et al., 2015; Lashmar et al., 2018; Schiavo et al., 2021a) and using the following parameters: (1) the minimum number of consecutive homozygous SNP was 15; (2) the minimum region length to define a $\mathrm{ROH}$ was $1 \mathrm{Mb}$, which excluded short $\mathrm{ROH}$ due to high linkage disequilibrium; (3) a maximum of 2 heterozygous SNP was allowed; (4) the minimum allowed density of SNP in a genome window was one SNP in $100 \mathrm{~kb}$; (5) the maximum allowed distance between consecutive SNP was $1 \mathrm{Mb}$. Five classes of $\mathrm{ROH}$ were defined depending on the ROH length, according to Kirin et al. (2010): 1 to $2 \mathrm{Mb}, 2$ to $4 \mathrm{Mb}$, 4 to $8 \mathrm{Mb}, 8$ to $16 \mathrm{Mb},>16 \mathrm{Mb}$. For each animal, the total number of detected $\mathrm{ROH}$, the average length of $\mathrm{ROH}$ (LROH) and the total sum of ROH segments 

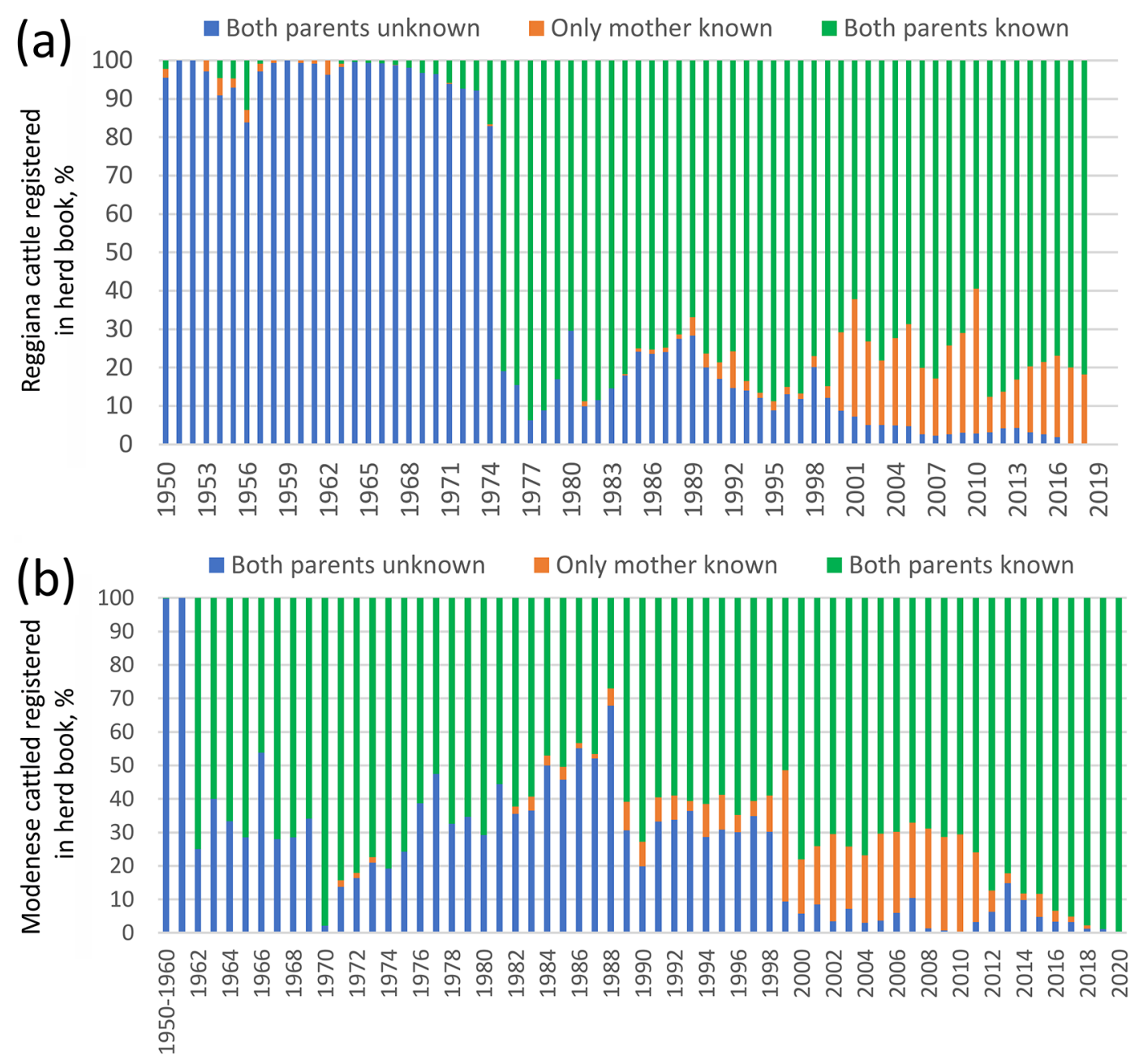

Figure 1. Evolution of pedigree data of the cattle registered in the Reggiana (a) and Modenese (b) herd books showing the percentage of individual animal records with both parents unknown (blue bars), with only the mother known (orange bars), or with both parents known (green bars).

(SROH) in $\mathrm{Mb}$ was calculated. These values were also averaged for the 2 breeds. Then, $\boldsymbol{F}_{\mathbf{R O H}}$ was computed as the proportion of the autosomal genome covered by $\mathrm{ROH}$, with the formula: $F_{\mathrm{ROH}}=\mathrm{SROH} / \mathrm{L}$ (Autosomes), where $\mathrm{L}$ (Autosomes) is the total length of the autosomal genome covered by the analyzed SNP. Different $F_{\mathrm{ROH}}$ were calculated, considering all $\mathrm{ROH}$ classes $(\mathrm{ROH} \geq 1$ $\left.\mathrm{Mb} ; \boldsymbol{F}_{\mathrm{ROH} 1}\right)$ or including $\mathrm{ROH} \geq 2 \mathrm{Mb}\left(\boldsymbol{F}_{\mathbf{R O H} 2}\right), \mathrm{ROH}$ $\geq 4 \mathrm{Mb}\left(\boldsymbol{F}_{\mathbf{R O H} 4}\right), \mathrm{ROH} \geq 8 \mathrm{Mb}\left(\boldsymbol{F}_{\mathbf{R O H} 8}\right)$ and $\mathrm{ROH} \geq 16$ $\mathrm{Mb}\left(\boldsymbol{F}_{\text {ROH16 }}\right)$, following the mentioned length classification criteria. PLINK 1.9 was also used to calculate the following genomic inbreeding parameters: (1) the difference between observed and expected number of homozygous genotypes $\left(\boldsymbol{F}_{\mathrm{HOM}}\right) ;(2)$ the diagonal elements of the genomic relationship matrix ( $\boldsymbol{F}_{\mathrm{GRM}}$; VanRaden et al., 2011). Other 3 inbreeding parameters were calculated using the GCTA software v1.92 (Yang et al., 2011): (1) the variance-standardized relationship minus
$1\left(\boldsymbol{F}_{\text {HAT1 }}\right) ;(2)$ the excess of homozygosity $\left(\boldsymbol{F}_{\text {HAT2 }}\right) ;(3)$ the correlation between uniting gametes $\left(\boldsymbol{F}_{\text {HAT3 }}\right)$.

Pearson correlations between all evaluated inbreeding coefficients, both based on pedigree information and genomic information, were calculated.

\section{Inbreeding Rate and Effective Population Size}

Population inbreeding rates were calculated in the following ways: (1) per year and (2) averaged per year over a time window defined by the generation interval obtained with ENDOG v4.8 (Table 1) and computed using a sliding step of 1 year. These population inbreeding rates were calculated using (1) pedigree data (for both $F_{\mathrm{PEDW}}$ and $\left.F_{\mathrm{PEDR}}\right)$, considering all pedigree information available in the herd books of the 2 breeds and considering only information from the genotyped animals, defined in this latter case as subpedigree; and (2) 
genomic-based estimates $\left(F_{\mathrm{ROH} 1}\right.$ and $F_{\mathrm{HOM}}$, defined above). The calculations were obtained as (1) the regression coefficient of the population averaged inbreeding values on the year of birth and on the defined time windows and (2) using the formula $\Delta \mathrm{F}=\frac{F_{t}-F_{t-1}}{1-F_{t-1}}$ (Falconer and Mackay, 1996), where $F$ is the averaged inbreeding at year $t$ or at the time window $t$ (as defined above). Effective population size was calculated with the formula $N e=\frac{1}{2 \Delta F}$ (Falconer and Mackay, 1996), where $\Delta F$ was estimated as the regression coefficient reported above or using the formula of Falconer and Mackay (1996) indicated above. The generation intervals computed with ENDOG was used to estimate the population inbreeding rates per generation. The standard error of the rates inbreeding per year has been used to estimate confidence intervals (Granado-Tajada et al., 2020)

Effective population size at recent generations was also computed using SNP data with the SNeP software v1.11 (Barbato et al., 2015), using the maximum distance between SNP to be analyzed of $10 \mathrm{Mb}$ and the binwidth of $100 \mathrm{~kb}$ for the calculation of linkage disequilibrium.

\section{Runs of Homozygosity Islands}

The proportion of SNP residing within a $\mathrm{ROH}$ was calculated for a given breed by counting the number of times a SNP appeared in a ROH divided by the total number of genotyped cattle of that breed. Then $\mathrm{ROH}$ islands were identified using a percentile threshold defined for each breed separately by selecting the top $1 \%$ SNP that were more frequently present in an $\mathrm{ROH}$ (Szmatoła et al., 2016; Purfield et al., 2017; Bertolini et al., 2018; Mastrangelo et al., 2018b; Zhang et al., 2018). An $\mathrm{ROH}$ island was considered if at least 2 adjacent SNP trespassed this threshold and if they were less than $1 \mathrm{Mb}$ far from each other. Annotations of these regions were retrieved from the GFF file of protein coding in ARS-UCD1.2 genes from NCBI with Bedtools v.2.17.0.

Over-representation analysis was used to identify biological features characterizing the identified genomic regions detected in Reggiana and Modenese, separately. Analyses were carried out with Enrichr (Chen et al., 2013) via Fisher's exact test. Interrogated gene sets belonged to the Gene Ontology Biological Process branch, the Kyoto Encyclopedia of Genes and Genomes (human), and the GWAS catalog (human; https://www .ebi.ac.uk/gwas/). Terms presenting at least 2 genes of the input set related to 2 or more windows and an adjusted $P<0.05$ were considered statistically enriched.

\section{RESULTS}

\section{Comparative Analysis of Inbreeding Parameters and $\mathrm{Ne}$ in the 2 Breeds}

Figure 2 reports the averaged $F_{\mathrm{PEDW}}, F_{\mathrm{PEDR}}$, and $F_{\mathrm{AR}}$ levels calculated using all available pedigree information for the animals of the 2 breeds that were born in each year between 1964 and 2018, which provided a complete picture of the information available in the Reggiana and Modenese Herd Books. The increasing trend of the inbreeding level is evident from the 3 parameters and in both breeds. As expected from the calculation methods, $F_{\mathrm{PEDR}}$ gave a general averaged higher level of inbreeding than what was obtained from $F_{\text {PEDW }}$, which does not deal with missing pedigree information.

The genotyped Reggiana and Modenese cattle corresponded to about two-thirds of the extant cow populations of both breeds in the year 2019, that is the year in which most of the sampling and genotyping were carried out. Table 2 summarizes the information on the different pedigree and genomic-derived inbreeding parameters calculated for the genotyped subpopulations of both breeds. Figure 3 reports the frequency distribution of the inbreeding levels calculated with 6 of these parameters in both breeds ( 3 derived from pedigree information: $F_{\mathrm{PEDW}}, F_{\mathrm{PEDR}}, F_{\mathrm{AR}} ; 3$ derived with genomic data: $F_{\mathrm{ROH} 1}, F_{\mathrm{HOM}}$, and $\left.F_{\mathrm{GRM}}\right)$. Different distributions could be observed among methods and between breeds with the same methods. These differences are mainly derived by the number of individual genotyped, by different inbreeding levels between the 2 populations and by the presence of animals with pedigree-based coefficient equal to 0 for some of the methods. For the genotyped subpopulations of the 2 breeds, the inbreeding trends based on the averaged inbreeding level of the animals born in different years (calculated for the same parameters mentioned above), for years including several animals higher or equal to 10, is reported in Figure 4. In general, $F_{\text {PEDW }}$ gave a lower level of inbreeding compared with $F_{\text {PEDR }}$ (as already mentioned before), $F_{\mathrm{AR}}$, and $F_{\mathrm{ROH} 1}$ parameters, which are based on similar concepts or assumptions and are represented in a more usual scale that better resembles the identity by descent. Pedigree-derived information indicated a general lower level of inbreeding in the Modenese breed than in the Reggiana breed. However, this picture is reversed when genomic inbreeding parameters are considered: genomic inbreeding estimates are indeed, in general, higher in the Modenese breed than in the Reggiana breed.

The correlation coefficients between inbreeding estimates of the genotyped animals are shown in Table 3 and in Supplemental Figure S2 (https://doi.org/10 

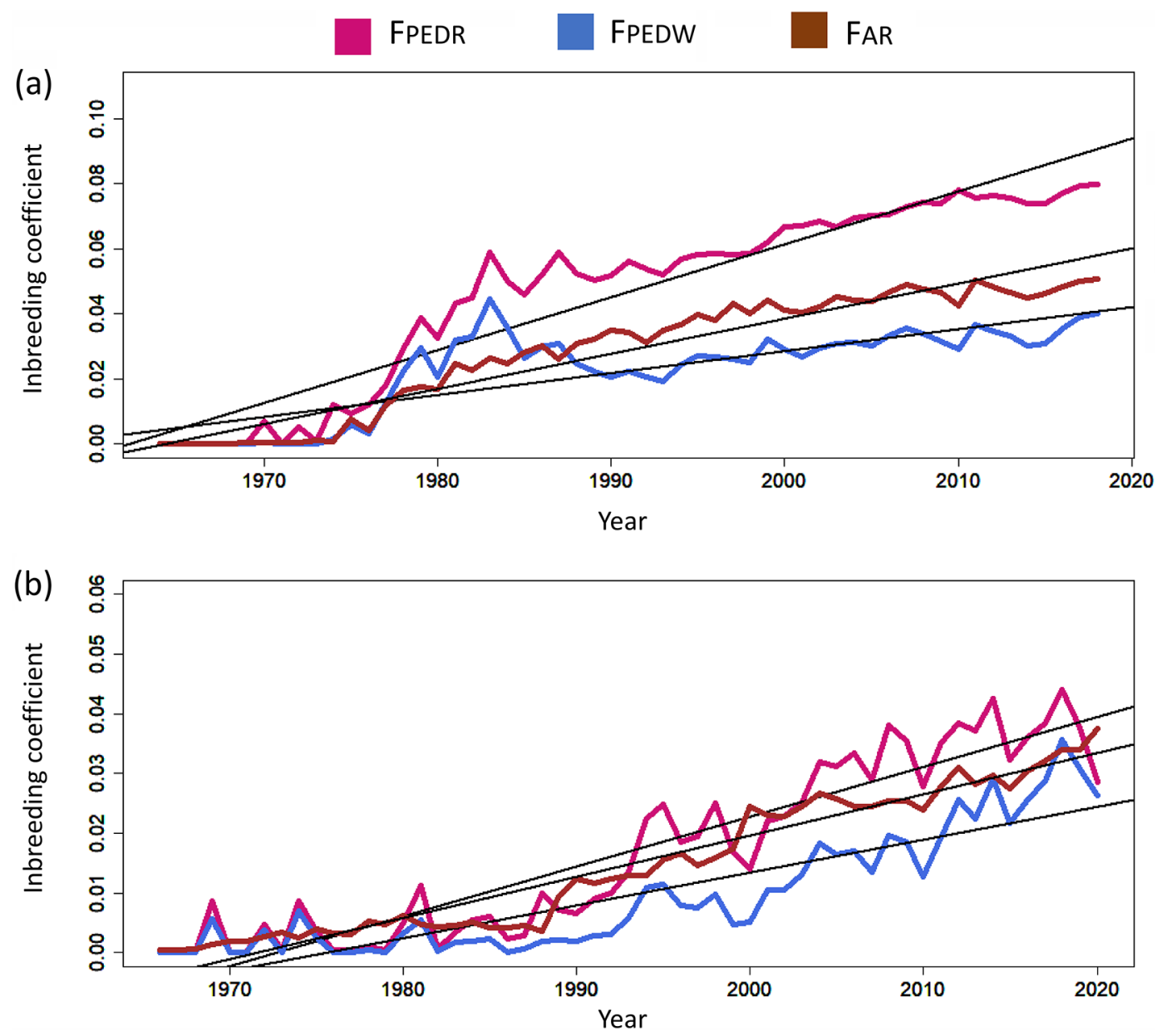

Figure 2. Average inbreeding coefficients computed by year for Reggiana (a) and Modenese (b) breeds with 3 pedigree-based methods: inbreeding coefficient estimated according to Wright's coefficient $\left(F_{\text {PEDW }}\right)$, in blue; inbreeding coefficient estimated with the recursive method $\left(F_{\mathrm{PEDR}}\right)$, in pink; and average relatedness $\left(F_{\mathrm{AR}}\right)$ in brown. Trend slopes are reported for each method.

Table 2. Main statistics of all inbreeding parameters calculated in Reggiana and Modenese breeds

\begin{tabular}{|c|c|c|c|c|c|c|}
\hline Parameter $^{1}$ & \multicolumn{3}{|c|}{ Reggiana } & \multicolumn{3}{|c|}{ Modenese } \\
\hline$F_{\mathrm{AR}}$ & $0.057(0.011)$ & 0.001 & 0.080 & $0.030(0.013)$ & 0.001 & 0.050 \\
\hline$F_{\mathrm{ROH} 1}$ & $0.066(0.038)$ & 0.001 & 0.388 & $0.088(0.042)$ & 0.003 & 0.356 \\
\hline$F_{\mathrm{ROH} 2}$ & $0.058(0.037)$ & 0.000 & 0.381 & $0.078(0.042)$ & 0.000 & 0.349 \\
\hline$F_{\mathrm{ROH} 16}$ & $0.021(0.027)$ & 0.000 & 0.328 & $0.031(0.031)$ & 0.000 & 0.267 \\
\hline$F_{\mathrm{HOM}}$ & $0.002(0.045)$ & -0.120 & 0.353 & $-0.017(0.049)$ & -0.133 & 0.282 \\
\hline$F_{\mathrm{GRM}}$ & $0.985(0.360)$ & 0.806 & 14.475 & $0.950(0.137)$ & 0.771 & 1.788 \\
\hline$F_{\mathrm{HAT} 1}$ & $-0.015(0.360)$ & -0.194 & 13.475 & $-0.050(0.137)$ & -0.229 & 0.788 \\
\hline$F_{\mathrm{HAT} 2}$ & $0.001(0.333)$ & -12.721 & 0.361 & $-0.015(0.128)$ & -0.677 & 0.298 \\
\hline$F_{\text {HAT3 }}$ & $0.003(0.039)$ & -0.057 & 0.387 & $-0.015(0.036)$ & -0.075 & 0.250 \\
\hline
\end{tabular}

${ }^{1} F_{\text {PEDR }}=$ inbreeding coefficients based on pedigree information computed according to the recursive method; $F_{\text {PEDW }}=$ inbreeding coefficients based on pedigree information estimated according to Wright's coefficient; $F_{\mathrm{AR}}=$ average relatedness calculated using pedigree information; $F_{\mathrm{ROH} 1}$ to $F_{\mathrm{ROH} 16}=5$ classes of runs of homozygosity $(\mathrm{ROH})$ defined by $\mathrm{ROH}$ length: $\mathrm{ROH} \geq 1 \mathrm{Mb}, \geq 2 \mathrm{Mb}, \geq 4 \mathrm{Mb}, \geq 8 \mathrm{Mb}$, and $\geq 16 \mathrm{Mb}$, respectively; $F_{\mathrm{HOM}}=$ difference between observed and expected number of homozygous genotypes; $F_{\mathrm{GRM}}=$ diagonal elements of the genomic relationship matrix; $F_{\mathrm{HAT} 1}=$ variance-standardized relationship minus $1 ; F_{\mathrm{HAT} 2}=$ excess of homozygosity; $F_{\mathrm{HAT} 3}=$ correlation between uniting gametes. 
(a)

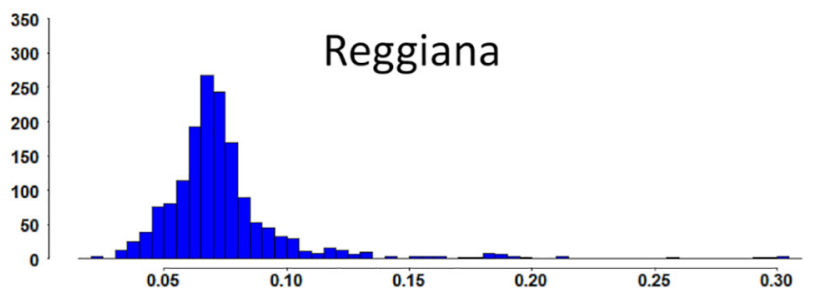

(b)

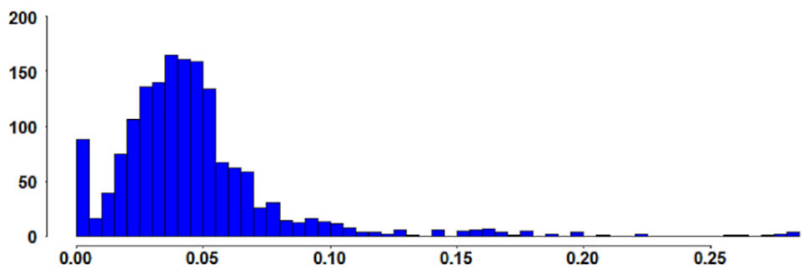

(c)

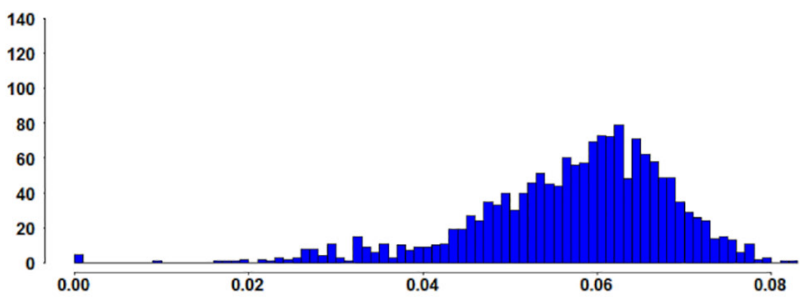

(d)

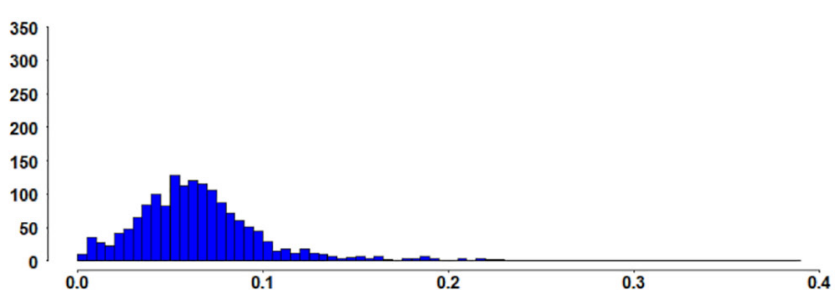

(e)

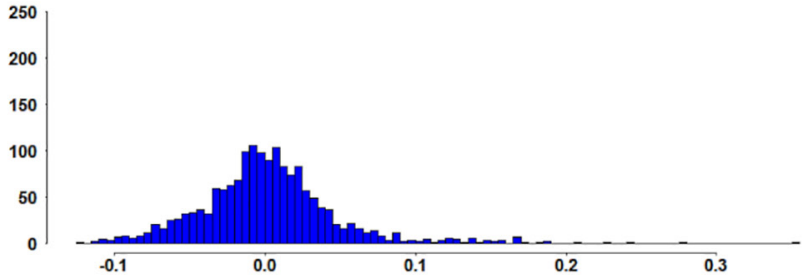

(f)

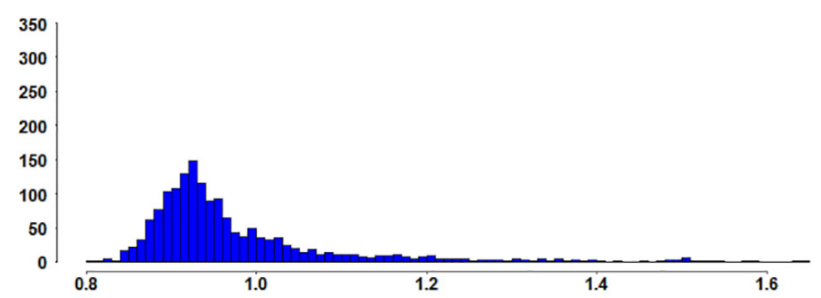

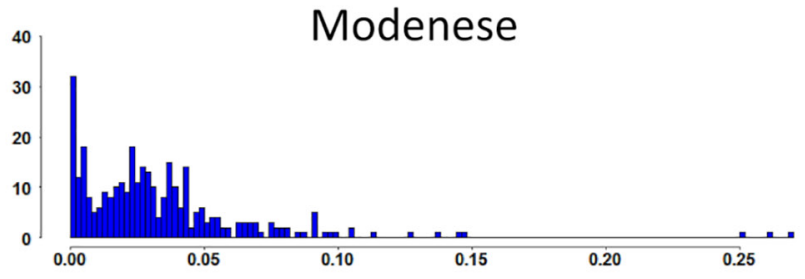
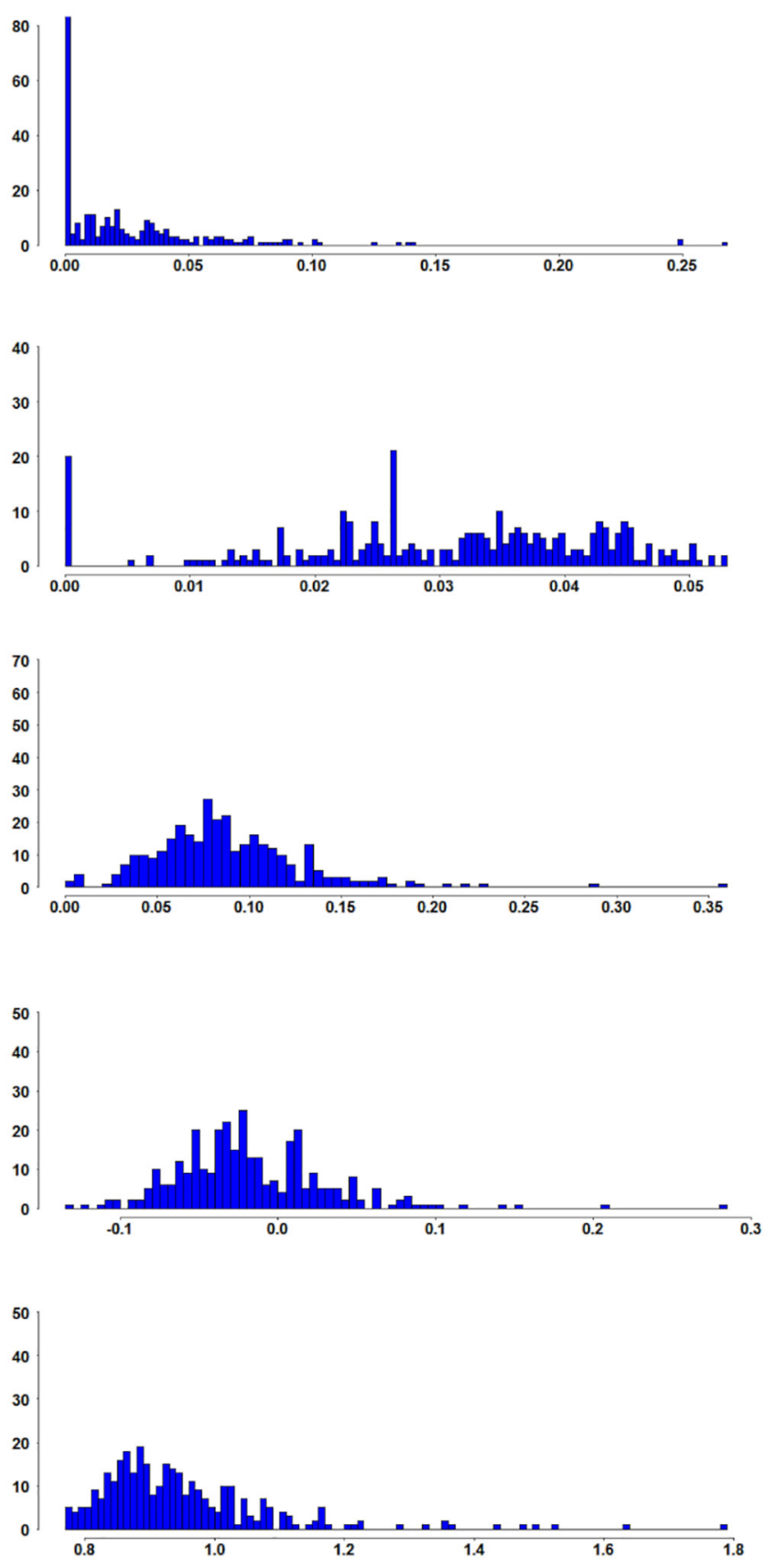

Figure 3. Frequency distribution (y-axis) of inbreeding coefficients computed with different methods in the 2 cattle breeds: (a) $F_{\text {PEDR }}$; (b) $F_{\mathrm{PEDW}}$; (c) $F_{\mathrm{AR}}$; (d) $F_{\mathrm{ROH} 1}$, (e) $F_{\mathrm{HOM}}$, and (f) $F_{\mathrm{GRM}}$. Parameters: $F_{\mathrm{PEDR}}=$ inbreeding coefficients based on pedigree information computed according to the recursive method; $F_{\mathrm{PEDW}}=$ inbreeding coefficients based on pedigree information estimated according to Wright's coefficient; $F_{\mathrm{AR}}=$ average relatedness calculated using pedigree information; $F_{\mathrm{ROH} 1}=\mathrm{ROH} \geq 1 \mathrm{Mb} ; F_{\mathrm{HOM}}=$ difference between observed and expected number of homozygous genotypes; $F_{\mathrm{GRM}}=$ diagonal elements of the genomic relationship matrix. 


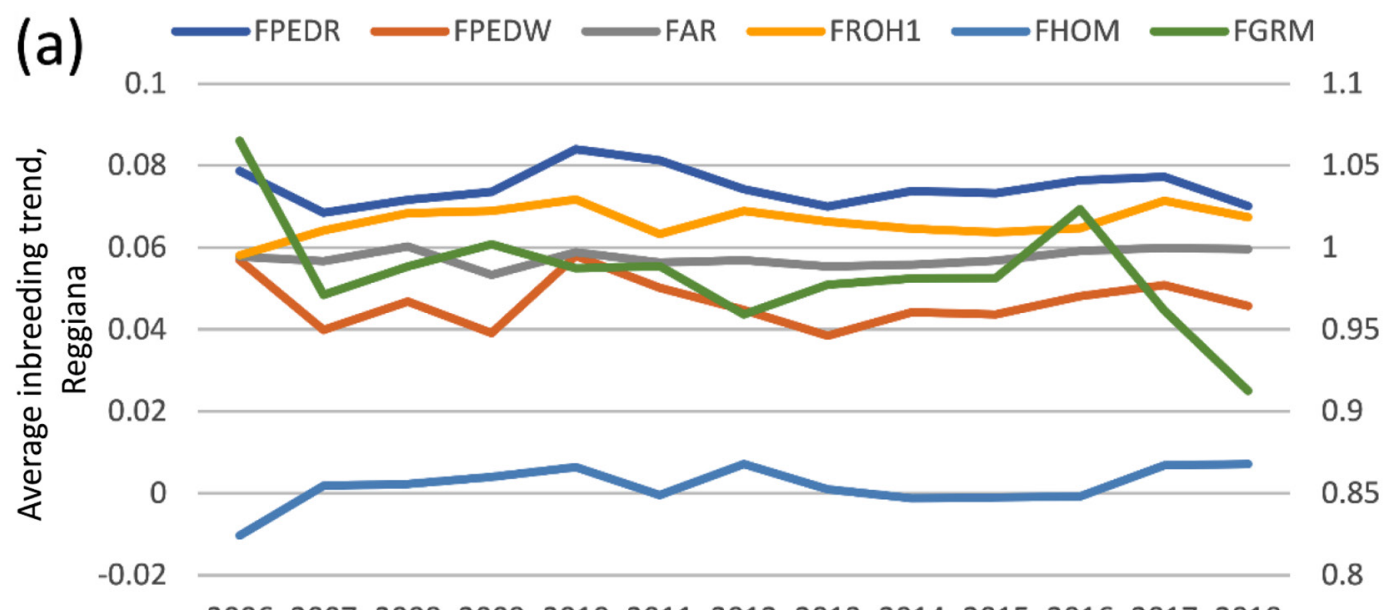

2006200720082009201020112012201320142015201620172018

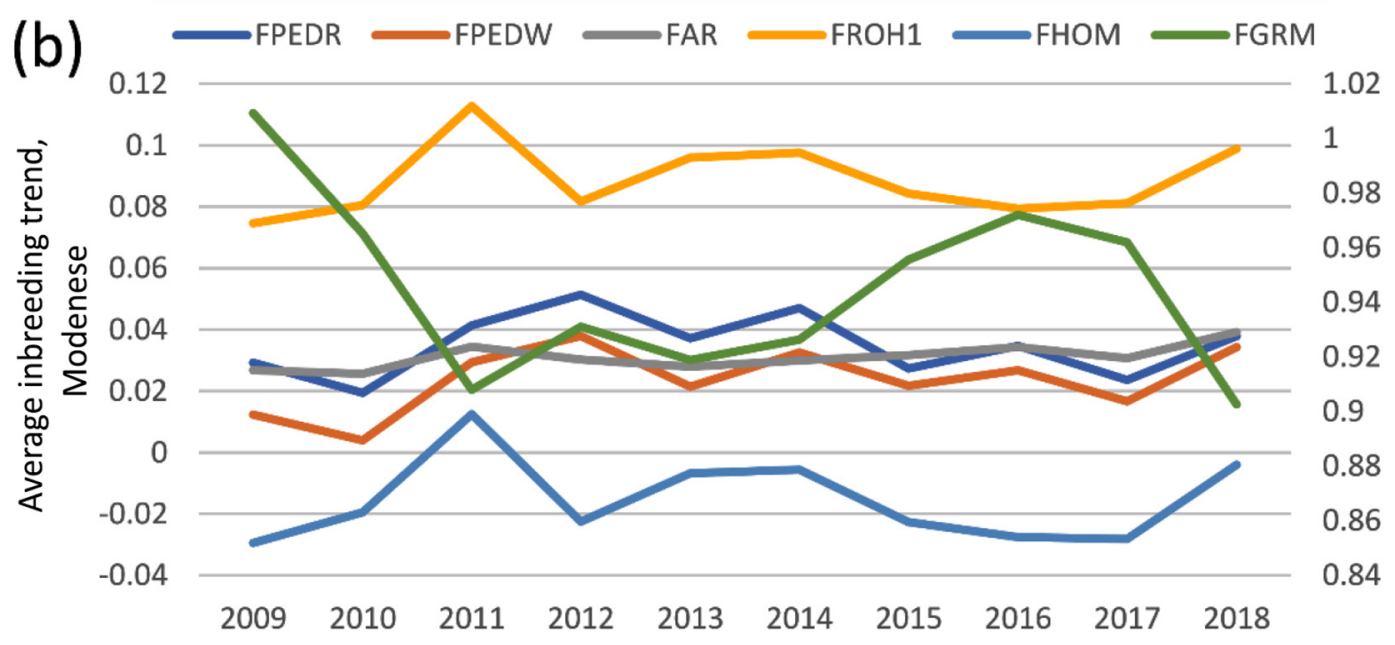

Figure 4. Average inbreeding trend of $F_{\mathrm{PEDW}}, F_{\mathrm{PEDR}}, F_{\mathrm{AR}}, F_{\mathrm{ROH} 1}, F_{\mathrm{HOM}}$ and $F_{\mathrm{GRM}}$ for each year from the genotyped subset of (a) Reggiana and (b) Modenese cattle. For both breeds, the axis on the right refers to $F_{\mathrm{GRM}}$ values only. Parameters: $F_{\text {PEDR }}=$ inbreeding coefficients based on pedigree information computed according to the recursive method; $F_{\mathrm{PEDW}}=$ inbreeding coefficients based on pedigree information estimated according to Wright's coefficient; $F_{\mathrm{AR}}=$ average relatedness calculated using pedigree information; $F_{\mathrm{ROH} 1}=\mathrm{ROH} \geq 1 \mathrm{Mb} ; F_{\mathrm{HOM}}=$ difference between observed and expected number of homozygous genotypes; $F_{\mathrm{GRM}}=$ diagonal elements of the genomic relationship matrix.

.5281 /zenodo.5532620; Schiavo et al., 2021b). For both breeds the estimates that used pedigree information are highly correlated with each other. For example, $F_{\text {PEDR }}$ and $F_{\text {PEDW }}$ have correlations of 0.895 and 0.949 in Reggiana and Modenese, respectively. Several estimates that used genomic information were highly correlated with each other in both breeds. These highly correlated parameters included all $\mathrm{ROH}$-derived estimates $\left(F_{\mathrm{ROH} 1}, F_{\mathrm{ROH} 2}, F_{\mathrm{ROH} 4}, F_{\mathrm{ROH} 8}\right.$, and $F_{\mathrm{ROH} 16}$, that are based on $\mathrm{ROH}$ of different minimum length). Considering $F_{\mathrm{ROH} 1}$ against all other $\mathrm{ROH}$ length parameters, the correlation ranged from 0.998 to 0.902 in the Reggiana and from 0.998 to 0.911 in the Modenese breeds. All $\mathrm{ROH}$-derived inbreeding parameters were also highly correlated with $F_{\mathrm{HOM}}$ (from 0.961 to 0.831 in Reggiana and from 0.981 to 0.895 in Modenese), with decreasing correlation related to the increasing minimum length of the ROH considered. All $F_{\mathrm{ROH}}$ were also moderately correlated with $F_{\mathrm{HAT} 3}$ (from 0.654 to 0.687 in Reggiana and from 0.707 to 0.546 in Modenese), with increasing correlation related to the increasing minimum length of the $\mathrm{ROH}$ considered in the Reggiana breed and the opposite in the Modenese breed. There was no general concordant level of correlations in the 2 breeds between $F_{\mathrm{HAT} 2}$ and all $F_{\mathrm{ROH}}$ parameters (highly correlated in Modenese: from 0.707 to 0546 ; poorly correlated in Reggiana: from 0.231 to 0.165 ). Negative and very low correlations were observed between $F_{\mathrm{HAT} 1}$ and all other genomic inbreeding parameters in both breeds, except for $F_{\mathrm{HAT} 2}$ and $F_{\mathrm{HAT} 3}$ (and $F_{\mathrm{GRM}}$ ). For the first parameter, highly negative correlations were observed in both breeds ( -0.977 in Reggiana and -0.857 in Modenese), 
whereas against the second parameter, correlations were moderate and positive ( 0.480 and 0.380 , respectively).

Correlation between pedigree and genomic-based parameters were in general low and in several cases not significant. Correlations between $F_{\mathrm{PEDR}}$ and all $F_{\mathrm{ROH}}$ parameters ranged between 0.187 to 0.195 and 0.319 to 0.323 in the Reggiana and Modenese breeds, respectively. The correlation slightly tended to increase according to the increase of $\mathrm{ROH}$ minimum length considered to the $F_{\mathrm{ROH} 8}$ in Reggiana and to the $F_{\mathrm{ROH} 16}$ in Modenese. Correlations between the other similar derived $F_{\text {PED }}$ parameter $\left(F_{\mathrm{PEDW}}\right)$ and all $F_{\mathrm{ROH}}$ measures were lower than those observed between $F_{\mathrm{PEDR}}$ and all $F_{\mathrm{ROH}}$ measures. The inbreeding coefficients derived from long $\mathrm{ROH}$, $F_{\mathrm{ROH} 16}$ and $F_{\mathrm{ROH} 8}$, had a low correlation in both breeds with ancient inbreeding value. The main comparisons between these approaches are reported in Supplemental Table S1 (https://doi.org/10.5281/zenodo.5532620; Schiavo et al., 2021b).

Inbreeding rates calculated for the genotyped subpopulations of both breeds are summarized in Table 4 . The rate of inbreeding per generation $(\Delta F$ and regression) of genotyped animals was higher with pedigreebased estimates than with $F_{\mathrm{ROH} 1}$ in both breeds. Even if the Modenese data sets was smaller and some of the trends and overall pictures that could be observed in this breed should be considered with caution, it seems that the increasing trend was higher in Modenese than in Reggiana breed.

Effective population size in the 2 breeds estimated with several methods is reported in Table 4. The effective population size estimated with all methods was always higher in Reggiana than in Modenese, also reflecting, to some extent, the current total population size of the 2 breeds. The effective population size in Reggiana ranged from a minimum of 63 estimated using $F_{\text {PEDR }}$ data to a maximum of 714 estimated using $F_{\mathrm{ROH} 1}$ data, whereas in Modenese this parameter ranged from a minimum of 19, estimated with $F_{\mathrm{ROH} 1}$ data, to a maximum of 74 , estimated with $\mathrm{SNeP}$ data.

\section{Runs of Homozygosity Profiles and Islands in Reggiana and Modenese Breeds}

A high correlation between the number of $\mathrm{ROH}$ and the total length of the autosomal genome covered by $\mathrm{ROH}(\mathrm{SROH})$ was observed in both breeds, namely 0.74 for Reggiana and 0.68 for Modenese (Supplemental Figure S2; https://doi.org/10.5281/zenodo.5532620; Schiavo et al., 2021b). Table 5 summarizes the main characteristics of the $\mathrm{ROH}$ identified in the cattle of the 2 breeds. Modenese cattle had a higher average length of $\mathrm{ROH}$, a higher average number of $\mathrm{ROH}$ per animal and a higher averaged fraction of the genome

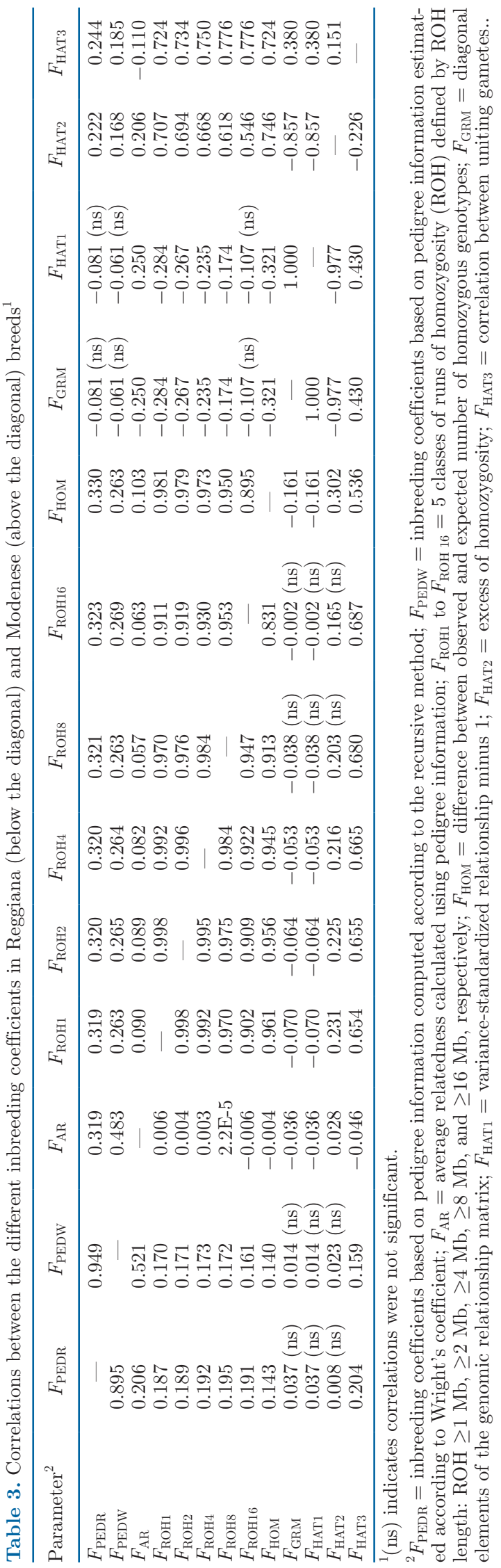


Table 4. Mean inbreeding rate per generation across years calculated in sliding windows define by generation interval $(\Delta F \pm \mathrm{SE})$, derived effective population size $(\mathrm{Ne})$ and the confidence interval estimated for $N e$ in the Reggiana and Modenese breeds calculated for the whole herd book pedigreed populations, for the pedigree subsets, or for the genotyped subpopulations (gsp), considering different inbreeding parameters

\begin{tabular}{|c|c|c|c|c|c|c|}
\hline \multirow[b]{2}{*}{ Parameter $^{1}$} & \multicolumn{2}{|c|}{ Reggiana } & \multirow[b]{2}{*}{ CI } & \multicolumn{2}{|l|}{ Modenese } & \multirow[b]{2}{*}{ CI } \\
\hline & $\Delta F$ & $\mathrm{Ne}$ & & $\Delta F^{2}$ & $\mathrm{Ne}$ & \\
\hline$F_{\text {PEDW }}$ & $0.0032 \pm 0.0101$ & 156 & 0.000219 & $0.0072 \pm 0.0052$ & 69 & 0.000171 \\
\hline$F_{\mathrm{PEDR}}$ & $0.0079 \pm 0.0090$ & 63 & 0.000213 & $0.0092 \pm 0.0071$ & 54 & 0.000245 \\
\hline$F_{\mathrm{AR}}$ & $0.0051 \pm 0.0048$ & 98 & 0.000146 & $0.0077 \pm 0.0034$ & 64 & 0.000096 \\
\hline$F_{\text {PEDW subset }}$ & $0.0032 \pm 0.0101$ & 156 & 0.000204 & $0.0070 \pm 0.0059$ & 71 & 0.000226 \\
\hline$F_{\text {PEDR subset }}$ & $0.0079 \pm 0.0090$ & 63 & 0.000209 & $0.0089 \pm 0.0072$ & 56 & 0.000181 \\
\hline$F_{\mathrm{AR} \text { subset }}$ & $0.0051 \pm 0.0054$ & 98 & 0.000152 & $0.0075 \pm 0.0038$ & 66 & 0.000097 \\
\hline$F_{\text {PEDW gsp }}$ & $0.0024 \pm 0.0132$ & 208 & 0.001043 & 0.0088 & 56 & 0.002821 \\
\hline$F_{\text {PEDR gsp }}$ & $0.0018 \pm 0.0094$ & 278 & 0.001697 & 0.0223 & 22 & 0.001566 \\
\hline$F_{\mathrm{AR} g \mathrm{sp}}$ & $0.0017 \pm 0.0045$ & 294 & 0.002206 & 0.0128 & 39 & 0.003223 \\
\hline$F_{\mathrm{ROH} 1 \mathrm{gsp}}$ & $0.0007 \pm 0.0051$ & 714 & 0.002924 & 0.0262 & 19 & 0.013240 \\
\hline$F_{\text {HOM gsp }}$ & $0.0012 \pm 0.0056$ & 417 & 0.003569 & 0.0247 & 20 & 0.013423 \\
\hline SNeP & - & 163 & & - & 74 & \\
\hline
\end{tabular}

${ }^{1} F_{\text {PEDR }}=$ inbreeding coefficients based on pedigree information computed according to the recursive method; $F_{\mathrm{PEDW}}=$ inbreeding coefficients based on pedigree information estimated according to Wright's coefficient; $F_{\mathrm{AR}}$ $=$ average relatedness calculated using pedigree information; $F_{\mathrm{ROH} 1}$ to $F_{\mathrm{ROH} 16}=5$ classes of runs of homozygosity $(\mathrm{ROH})$ defined by $\mathrm{ROH}$ length: $\mathrm{ROH} \geq 1 \mathrm{Mb}, \geq 2 \mathrm{Mb}, \geq 4 \mathrm{Mb}, \geq 8 \mathrm{Mb}$, and $\geq 16 \mathrm{Mb}$, respectively; $F_{\mathrm{HOM}}=$ difference between observed and expected number of homozygous genotypes; $F_{\mathrm{GRM}}=$ diagonal elements of the genomic relationship matrix; $F_{\mathrm{HAT} 1}=$ variance-standardized relationship minus $1 ; F_{\mathrm{HAT} 2}=$ excess of homozygosity; $F_{\mathrm{HAT} 3}=$ correlation between uniting gametes.

${ }^{2}$ For some parameters, the SE could not be calculated as generation interval covered just once the time window in which the data were available.

covered by $\mathrm{ROH}$ per animal as also defined from the higher values of the genomic inbreeding coefficients that were considered. These results are also confirmed by the higher percentage of long $\mathrm{ROH}$ in Modenese compared with the distribution of $\mathrm{ROH}$ length classes in Reggiana (Supplemental Figure S3; (https://doi .org/10.5281/zenodo.5532620; Schiavo et al., 2021b). The proportion of the autosomes of the 2 breeds covered by ROH is illustrated in Figure 5. In general, the smallest chromosomes tended to have a higher fraction of their total length covered by $\mathrm{ROH}$ in both breeds. Modenese breed had always a higher proportion of the chromosomes covered by $\mathrm{ROH}$ except for BTA13 and BTA23. The highest difference of coverage between the
2 breeds was observed for BTA6 where Modenese had almost the double percentage compared with what was observed in Reggiana.

The Manhattan plots reporting the position of the $\mathrm{ROH}$ islands identified in the Reggiana and Modenese breeds are reported in Figure 5. The $15 \mathrm{ROH}$ islands identified in Reggiana were located in 11 different chromosomes and covered, on the whole, a total of 18 $\mathrm{Mb}$ of genome regions; on the other hand, the $14 \mathrm{ROH}$ islands identified in Modenese spanned a total of 15 $\mathrm{Mb}$, located in 11 different autosomes. Details of these regions, including all annotated genes are reported in Supplemental Table S2 (https://doi.org/10.5281/ zenodo.5532620; Schiavo et al., 2021b). Three ROH

Table 5. Runs of homozygosity (ROH) parameters in Reggiana and Modenese breeds

\begin{tabular}{llcc}
\hline Parameter $^{1}$ & Measures & Reggiana & Modenese \\
\hline LROH & Mean (SD) & $4,629.052 \pm 1,726.621$ & $5,290.68 \pm 1,842.942$ \\
& Minimum & $1,128.13$ & $1,202.82$ \\
SROH & Maximum & $16,954.8$ & $15,831.5$ \\
& Mean (SD) & $165,365.9 \pm 93,011.110$ & $219,456 \pm 103,776.400$ \\
nROH & Maximum & $2,416.07$ & $8,419.77$ \\
& Mean (SD) & 966,426 & 886,563 \\
Number of SNPs & Minimum & $34.072 \pm 9.622$ & $40.341 \pm 9.771$ \\
in a ROH & Maximum & 2 & 7 \\
& Minimum & $261.388 \pm 357.300$ & 88 \\
& Maximum & 19 & $293.299 \pm 399.790$ \\
\hline
\end{tabular}

${ }^{1} \mathrm{LROH}=$ average length of $\mathrm{ROH}$ in $\mathrm{kb} . \mathrm{SROH}=$ total sum of $\mathrm{ROH}$ segments per animal in $\mathrm{kb} . \mathrm{nROH}=$ total number of $\mathrm{ROH}$ segment per animal. 
(a)

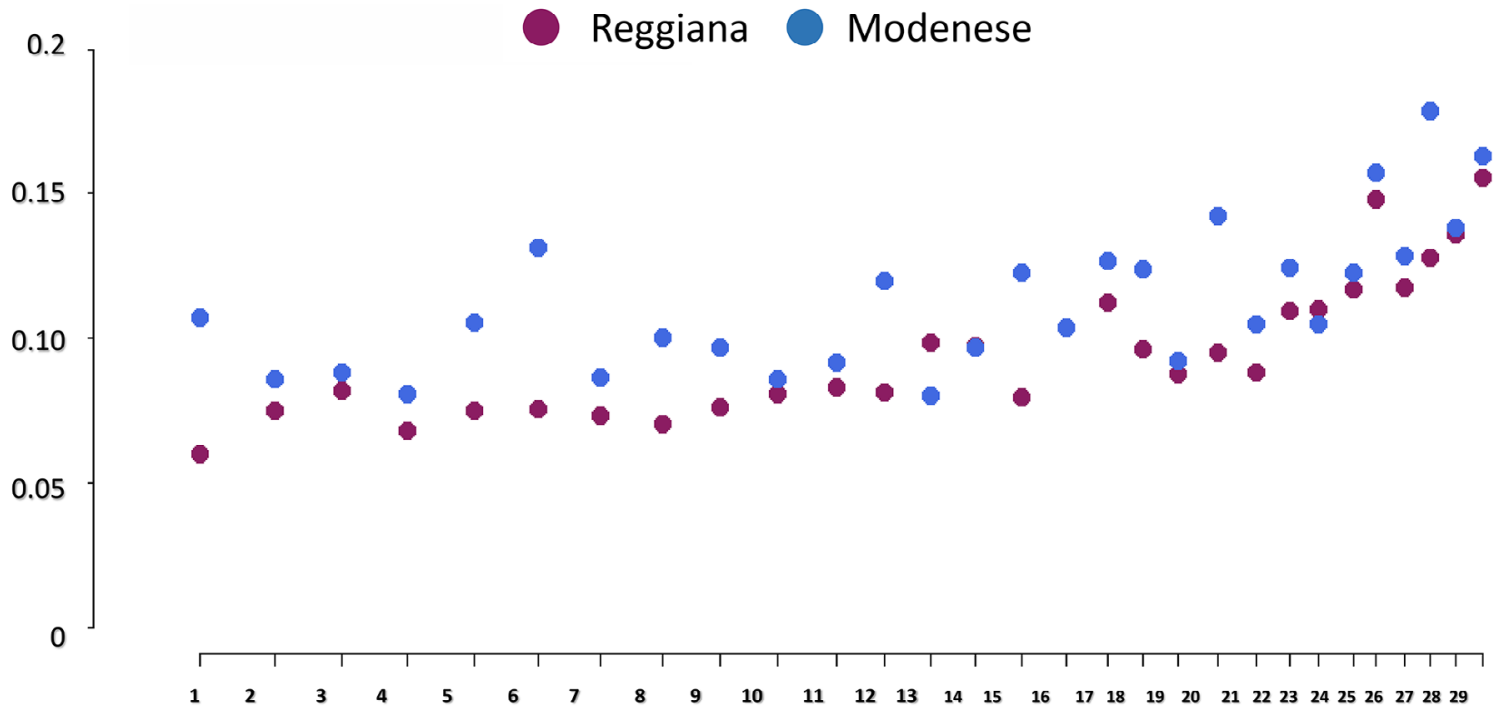

(b)

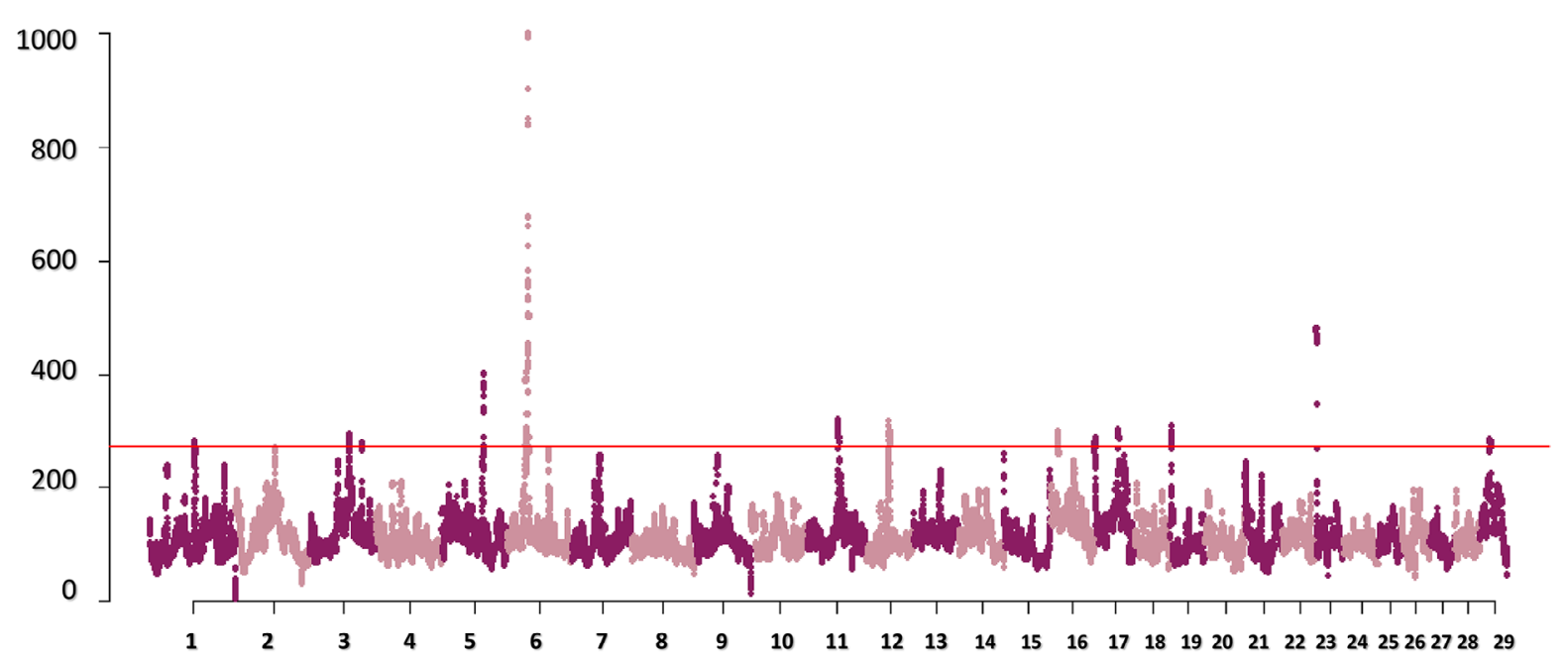

(c)

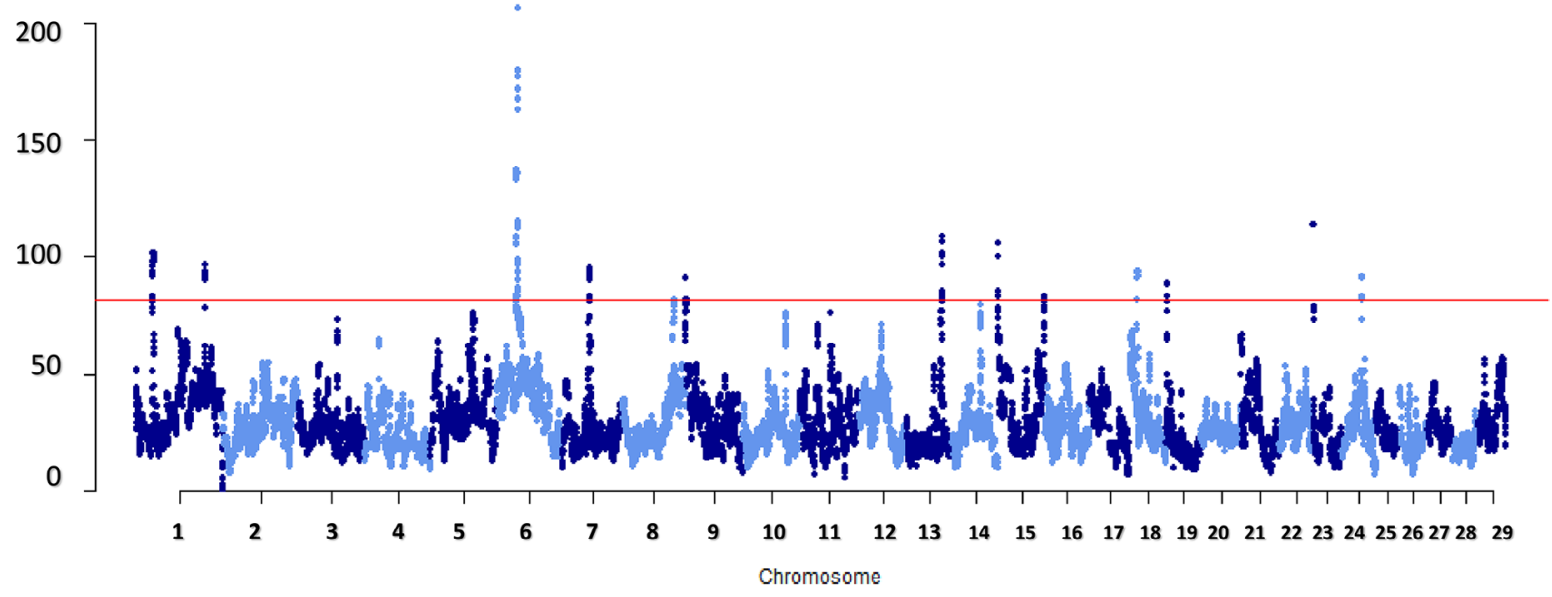

Figure 5. (a) The graphical representation of the proportion of runs of homozygosity (ROH) coverage in each autosomal chromosome in the 2 breeds aligned with Manhattan plots reporting the ROH islands identified in (b) Reggiana and (c) Modenese breeds. The red threshold in the Manhattan plots identifies the frequency in the population of the top $1 \%$ of most frequently homozygous SNPs. 
island regions overlapped between the 2 breeds: one on BTA6, one on BTA19, and one on BTA23. The region on BTA6 (from positions 35.87 to $38.62 \mathrm{Mb}$ ) is reported in more than two-thirds of all animals genotyped for both breeds. About 30 genes, including the $A B C G 2$ gene, are annotated in this chromosome region, which has been shown to be associated with milk yield and composition (Cohen-Zinder et al., 2005), and the NCAPG and $L C O R L$ genes that have been already reported to affect stature, body structure, and conformation in cattle and several other mammals (e.g., Nkrumah et al., 2007; Setoguchi et al., 2009; Pryce et al., 2011; Fontanesi et al., 2012; Bolormaa et al., 2014; Randhawa et al., 2015; Bouwman et al., 2018). The BTA19 ROH island region in common between Reggiana and Modenese spans from position 1.29 to $2.04 \mathrm{Mb}$ and includes the $C A 10$ gene. The other common ROH island region on BTA23, that was reported in about one-third of all genotyped animals for both breeds, encompasses the KHDRBS2 gene.

Among the top $3 \mathrm{ROH}$ islands identified in Reggiana, a region on BTA5 spanning from 75.89 to $77.15 \mathrm{Mb}$ was identified in about $20 \%$ of the investigated cattle. This region includes 12 annotated genes whose function, in general, is not well described or defined yet (Supplemental Table S2). The third top ROH island identified in Modenese (reported in about one-third of the analyzed animals) is located on BTA13 (from 63.31 to $64.45 \mathrm{Mb}$ ) includes the $A S I P$ gene that is well known to affect coat color in mammals. Among the other $\mathrm{ROH}$ islands identified in Modenese, a region on BTA18 contains the $M C 1 R$ gene, that is responsible for the variability at the extension coat color locus.

Gene enrichment analysis highlighted associations with biological features reported in the Human GWAS catalog (Supplemental Table S3; https://doi.org/10 .5281/zenodo.5532620; Schiavo et al., 2021b). Although analysis of the Reggiana gene set did not return any significant results, Modenese was enriched for genes related to coat colors related phenotypes (e.g., human hair color, skin color saturation, tanning) and body size related phenotypes (i.e., waist-to-hip ratio), in agreement to the results that were described above.

\section{DISCUSSION}

A proper management of local cattle genetic resources is essential to ensure their long-term sustainable conservation and, where possible, improvement for economically relevant traits. To this aim, the monitoring of the inbreeding rate of autochthonous breeds is one of the most important activities that intends to control the unavoidable increase that usually occurs in small populations. In this study we analyzed the level of inbreeding of 2 Italian autochthonous cattle breeds that are considered the icons of a typical dairy production system of the North of Italy that is based on the production of Parmigiano-Reggiano cheese, one of the most important PDO animal-derived product in Europe. Several inbreeding parameters calculated using pedigree (taking the whole herd book data sets) and genomic data (about two-thirds of the extant cattle populations) were used to analyze their relationships and to identify potential issues needed to improve the monitoring of this critical aspect in the conservation of these animal genetic resources (i.e., Reggiana and Modenese breeds). All parameters that were considered include approximations and rely on several assumptions that might not always hold in all breeds and conditions. In particular, the most critical issue is that pedigree information should be complete and correct. Pedigree information from past generations, however, could not be retrospectively completed or corrected apart from obvious and material registration errors. Genomic inbreeding measures derived by $\mathrm{ROH}$, that estimate the proportion of homozygous chromosome regions with respect to the total autosomal genome, can be called using different SNP parameters that might also depend on several intrinsic features of the SNP chip, such as density and the errors in detecting homozygous SNP (e.g., Purfield et al., 2012; Ferenčaković et al., 2013a,b; Ceballos et al., 2018; Rodríguez-Ramilo et al., 2019). We have already shown that, despite some small differences, all measures derived from different $\mathrm{ROH}$ calling approaches are usually highly correlated (Schiavo et al., 2020b); therefore, strong biases in estimating inbreeding derived by these genomic parameters are not expected. Based on the results obtained in this study, 2 groups of genomic inbreeding measures could be considered: one group includes all $\mathrm{ROH}$ related measures $\left(F_{\mathrm{ROH} 1}-F_{\mathrm{ROH} 16}\right), F_{\mathrm{HOM}}$ and $F_{\mathrm{HAT} 3}$ that had, in general, high correlation values to each other in both breeds (ranging from 0.654 to 0.998); another group includes $F_{\mathrm{GRM}}, F_{\mathrm{HAT} 1}$ and $F_{\mathrm{HAT} 2}$ that had, in general, low absolute correlation values with all other parameters or inconsistent values across the 2 breeds. This is also similar to what could be possible to infer from the same parameters analyzed in commercial and local pig breeds (Schiavo et al., 2020b).

The pedigree structures for the 2 breeds, dated back of about 60 years (starting from the constitution of their herd books), showed a general trend over this time frame that tended to substantially increase the proportion of registered animals with both parents known (Figure 1). This is similar to what might be expected, according to the better organization of the herd books in recent times, as also reported in other breeds (e.g., Granado-Tajada et al., 2020). A relevant frac- 
tion (about 10\%) of the Reggiana cattle registered over the last decade, however, had only information from the mother resulting in a lower number of complete generations in this breed than that of Modenese (Table $1)$. The effect of this incomplete pedigree structure caused a lower correlation between $F_{\text {PEDR }}$ and $F_{\text {PEDW }}$ in Reggiana (0.895) than in Modenese (0.949), when the genotyped subpopulation (that was quite recent: all genotyped animals were born from 2000 to 2018 and most of them were born over the last decade) was considered. This was also evident from the correlation between $F_{\mathrm{AR}}$ and the other 2 pedigree-based measures ( $F_{\text {PEDR }}$ and $\left.F_{\text {PEDW }}\right)$, even if the level of these values was much lower in both breeds as $F_{\mathrm{AR}}$ is affected by the completeness of the pedigree information (Gutiérrez and Goyache, 2005). In general, pedigree-based inbreeding parameters in the genotyped subpopulations indicated a higher mean inbreeding value in Reggiana than in Modenese. This situation was reverted when $\mathrm{ROH}$ genomic inbreeding parameters $\left(F_{\mathrm{ROH} 1}-F_{\mathrm{ROH} 16}\right)$ were considered: Modenese breed had always higher values than Reggiana breed. The actual general higher level of inbreeding in the Modenese breed can be indirectly confirmed by the lower $\mathrm{Ne}$ estimated with all used methods in this breed than in Reggiana cattle.

The higher depth of pedigree information in Modenese breed also resulted in higher correlation values between pedigree and all genomic inbreeding parameters in this breed than in Reggiana. However, these correlation values were in general low in both breeds. All other genomic-derived parameters were very poorly correlated with pedigree inbreeding values in both breeds, also reflecting the general low correlation between them and the second group of genomic inbreeding parameters defined above. Again, this situation might also be due, to some extent, by the higher proportion of registered Reggiana cattle born over the last 2 decades with incomplete pedigree information, that, in turn, might determine the lower equivalent number of complete generations available in the Reggiana breed than in Modenese cattle. Similar low correlations between pedigree-derived and genomic-derived inbreeding parameters have been already reported in several local breeds in which the semi-extensive/extensive production systems or the low technical inputs might contribute to reduce the correctness of the registration of the pedigree information (Peripolli et al., 2018b; Joaquim et al., 2019; Schiavo et al., 2020b). However, even greater correlations than those obtained in this study have been reported, particularly in horses (i.e., 0.65 in Italian Heavy Draft Horse autochthonous population; Mancin et al., 2020) and sheep (Granado-Tajada et al., 2020). It is possible that despite the sometime small population size, pedigree information in horses have been always recovered more accurately and have been started earlier than in local cattle breeds. A more precise use of artificial insemination could have been used to improve the correctness of the pedigree. Additionally, it has to be taken into account that both Reggiana and Modenese are examples of populations that experienced recent enlargements in the number of herds due to the success of the labeled cheese production within the PDO Parmigiano-Reggiano cheese, that has brought many economic benefits to farmers. However, in conservation programs such as in the present breeds as well as in other small breeds, the systematic use of genotyping tools to analyze the whole breed population has been demonstrated to be useful to overcome the limitations that the management of local genetic resources has to face if it is constructed only on pedigree recorded information (Purfield et al., 2017).

The $\mathrm{ROH}$ islands detected by analyzing genome data at the breed level pointed out hotspots of homozygosity that can be interpreted as the results of positive selection for alleles that might confer some adaptive advantages to the production systems where the breeds have been constituted (Mastrangelo et al., 2016). These highly homozygous regions can be the remain of signatures of past recent selections that differentiated local genetic resources (Burren et al., 2016). The preliminary study that investigated $\mathrm{ROH}$ islands in Reggiana breed based only on about 160 sires genotyped with the Illumina 50K SNP chip reported 8 hotspots of homozygosity on 6 different autosomes (Mastrangelo et al., 2018b). Among them, 2 (one on BTA6 and one on BTA29; Supplemental Table S3) overlap with the ROH islands identified in the current broader study. The region on BTA6, that barely trespassed the considered threshold in Mastrangelo et al. (2018b), corresponding to the frequency of the $10 \%$ of the genotyped animals, was the most relevant $\mathrm{ROH}$ island in both Reggiana and Modenese breeds. This region, that was detected in more than two-thirds of the analyzed animals of both breeds, includes the $A B C G 2$ and the NCAPG-LCORL genes. A missense mutation determining a potential causative variant affecting milk production and composition traits in cattle (Cohen-Zinder et al., 2005) has been already tested in Reggiana sire, confirming the high level of homozygosity of this gene region (Fontanesi et al., 2015). The NCAPG-LCORL genes have been shown to affect stature, several other conformations, carcass, and growth-related traits in different cattle populations (Lindholm-Perry et al., 2011). In a recent GWAS we carried out in Reggiana, this region was highly associated with the stature of the cows (Bovo et al., 2021). The quite high stature of both Reggiana and Modenese cattle could be influenced by this region that seems a remain of the past triple-purpose adaptation of these local breeds. This hypothesis is corroborated 
by the presence of many signatures of selection in the Reggiana genome that could be ascribed to the past unspecialized use of this breed (Bertolini et al., 2020). In Modenese, another interesting $\mathrm{ROH}$ island was localized on BTA13 in the region of the ASIP gene. Variants in this gene are responsible for the allele series at the Agouti coat color locus that determine a large coat color variability in many species, even if in cattle the role of the ASIP gene in affecting pigmentation has been elusive thus far. Recently, Trigo et al. (2021) reported that, in Nellore cattle, the degree of dark extension over a white color is determined by a composite deletion in the ASIP gene. White coat color associated with copy number variants affecting this gene have been reported in sheep and goats (Norris and Whan, 2008; Fontanesi et al., 2009, 2010a,b,c). Therefore, we could speculate that variants in the ASIP gene or regulating its expression might be involved in determining the white coat color and its deviations in Modenese cattle. To our knowledge, this would be the first case of a Bos taurus breed for which variability affecting the ASIP gene are associated with the characterizing coat color of the Modenese cattle. Another region in Modenese, detected on BTA18, includes an epistatic gene affecting coat color (MC1R; Russo et al., 2007). The combination of the effects derived by $A S I P$ and $M C 1 R$ could be important to define the coat color of this breed. This region could not be evidenced in Reggiana, despite the fact that most animals of this breed have the homozygous $e / e$ genotype at this gene, which confers the classical red coat color of this breed (Russo et al., 2007; Bovo et al., 2021). This is probably due to the small region that is almost fixed in this breed and that could not be captured with the method we applied. We are analyzing the genome of the breeds with other approaches to evidence additional signatures of selection that could complement and complete the results obtained by using $\mathrm{ROH}$ islands.

\section{CONCLUSIONS}

This study reports a detailed analysis of the inbreeding in 2 autochthonous cattle breeds, both using pedigree and genomic information, that made it possible to evaluate the effectiveness of pedigree information in local breeds that have ongoing plans of conservation but with a history of recent expansion of the population size. The different genomic estimates reported a limited increase of the inbreeding level over the last decades, suggesting a good breeding management of both breeds. The comparison between pedigree-based and genomic-based methods demonstrated the importance to apply genomic information in local populations such as Reggiana and Modenese to complement the incompleteness of the pedigree records. Signatures of selection, identified in the correspondence of $\mathrm{ROH}$ islands, explaining, at least in part, some breed-specific features, remained in the 2 breeds, despite the recent population size expansions after the major bottlenecks that both breeds experienced. Conservation programs of these cattle genetic resources should maintain these genetic peculiarities identified in some chromosome positions enriched of highly homozygous regions, but at the time, have to control the inbreeding rate. The use of marker assisted selection for a few of these regions (e.g., $M C 1 R$ alleles in the Reggiana cattle) can be optimized for this double purpose. Therefore, all animals of these 2 breeds are going to be genotyped with the same SNP chip already used in this study and for a few gene markers that could help to address a balanced conservation strategy driven by genomic information.

\section{ACKNOWLEDGMENTS}

This study is dedicated to the memory of Professor Vincenzo Russo (emeritus of the University of Bologna), whose efforts for the survival and conservation of the Reggiana and Modenese breeds have been widely appreciated by both farmers and the scientific community. We thank ANABORARE personnel, all Reggiana and Modenese farmers, veterinary and technician staff that collaborated in this study. This study was funded by the PSRN (Programma di Sviluppo Rurale Nazionale) 2014-2020 and 2020-2023, measure 10.2, Dual Breeding and Dual Breeding 2 projects (co-funded by the European Agricultural Fund for Rural Development of the European Union and by the Italian Ministry of Agriculture, Food and Forestry - MiPAAF) and by the University of Bologna RFO2019-2020 programs. The authors have not stated any conflicts of interest.

\section{REFERENCES}

Aguilar, I., and I. Misztal. 2008. Technical note: Recursive algorithm for inbreeding coefficients assuming nonzero inbreeding of unknown parents. J. Dairy Sci. 91:1669-1672. https://doi.org/10 .3168/jds.2007-0575.

Alemu, S. W., N. K. Kadri, C. Harland, P. Faux, C. Charlier, A. Caballero, and T. Druet. 2021. An evaluation of inbreeding measures using a whole-genome sequenced cattle pedigree. Heredity 126:410-423. https://doi.org/10.1038/s41437-020-00383-9.

ANABORARE (Associazione Nazionale Allevatori Bovini di Razza Reggiana). 2020. Il nuovo statuto. Accessed June 1, 2021. https:/ /www.razzareggiana.it/.

Banos, G., G. R. Wiggans, and R. L. Powell. 2001. Impact of paternity errors in cow identification on genetic evaluations and international comparisons. J. Dairy Sci. 84:2523-2529. https://doi.org/10 .3168/jds.S0022-0302(01)74703-0.

Barbato, M., P. Orozco-terWengel, M. Tapio, and M. W. Bruford. 2015. SNeP: A tool to estimate trends in recent effective population size trajectories using genome-wide SNP data. Front. Genet. 6:109. https://doi.org/10.3389/fgene.2015.00109. 
Baumung, R., J. Farkas, D. Boichard, G. Mészáros, J. Sölkner, and I. Curik. 2015. GRAIN: A computer program to calculate ancestral and partial inbreeding coefficients using a gene dropping approach. J. Anim. Breed. Genet. 132:100-108. https://doi.org/10.1111/jbg .12145 .

Bertolini, F., T. F. Cardoso, G. Marras, E. L. Nicolazzi, M. F. Rothschild, and M. Amills. 2018. Genome-wide patterns of homozygosity provide clues about the population history and adaptation of goats. Genet. Sel. Evol. 50:59. https://doi.org/10.1186/s12711-018 $-0424-8$.

Bertolini, F., G. Schiavo, S. Bovo, M. Sardina, S. Mastrangelo, S. Dall'Olio, B. Portolano, and L. Fontanesi. 2020. Comparative selection signature analyses identify genomic footprints in Reggiana cattle, the traditional breed of the Parmigiano-Reggiano cheese production system. Animal 14:921-932. https://doi.org/10.1017/ S1751731119003318.

Bolormaa, S., J. E. Pryce, A. Reverter, Y. Zhang, W. Barendse, K. Kemper, B. Tier, K. Savin, B. J. Hayes, and M. E. Goddard. 2014. A multi-trait, meta-analysis for detecting pleiotropic polymorphisms for stature, fatness and reproduction in beef cattle. PLoS Genet. 10:e1004198. https://doi.org/10.1371/journal.pgen .1004198.

Bouwman, A. C., H. D. Daetwyler, A. J. Chamberlain, C. H. Ponce, M. Sargolzaei, F. S. Schenkel, G. Sahana, A. Govignon-Gion, S. Boitard, M. Dolezal, H. Pausch, R. F. Brøndum, P. J. Bowman, B. Thomsen, B. Guldbrandtsen, M. S. Lund, B. Servin, D. J. Garrick, J. Reecy, J. Vilkki, A. Bagnato, M. Wang, J. L. Hoff, R. D. Schnabel, J. F. Taylor, A. A. E. Vinkhuyzen, F. Panitz, C. Bendixen, L. E. Holm, B. Gredler, C. Hozé, M. Boussaha, M. P. Sanchez, D. Rocha, A. Capitan, T. Tribout, A. Barbat, P. Croiseau, C. Drögemüller, V. Jagannathan, C. Vander Jagt, J. J. Crowley, A. Bieber, D. C. Purfield, D. P. Berry, R. Emmerling, K. U. Götz, M. Frischknecht, I. Russ, J. Sölkner, C. P. Van Tassell, R. Fries, P. Stothard, R. F. Veerkamp, D. Boichard, M. E. Goddard, and B. J. Hayes. 2018. Meta-analysis of genome-wide association studies for cattle stature identifies common genes that regulate body size in mammals. Nat. Genet. 50:362-367. https://doi.org/10.1038/ s41588-018-0056-5.

Bovo, S., G. Schiavo, H. Kazemi, G. Moscatelli, A. Ribani, M. Ballan, M. Bonacini, M. Prandi, S. Dall'Olio, and L. Fontanesi. 2021. Exploiting within breed variability in the autochthonous Reggiana breed identified several candidate genes affecting pigmentationrelated traits, stature and udder defects in cattle. Anim. Genet. 52:579-597. https://doi.org/10.1111/age.13109.

Burren, A., M. Neuditschko, H. Signer-Hasler, M. Frischknecht, I. Reber, F. Menzi, C. Drögemüller, and C. Flury. 2016. Genetic diversity analyses reveal first insights into breed-specific selection signatures within Swiss goat breeds. Anim. Genet. 47:727-739. https: //doi.org/10.1111/age.12476.

Ceballos, F. C., P. K. Joshi, D. W. Clark, M. Ramsay, and J. F. Wilson. 2018. Runs of homozygosity: Windows into population history and trait architecture. Nat. Rev. Genet. 19:220-234. https://doi .org/10.1038/nrg.2017.109.

Chang, C. C., C. C. Chow, L. C. A. M. Tellier, S. Vattikuti, S. M. Purcell, and J. J. Lee. 2015. Second-generation PLINK: Rising to the challenge of larger and richer datasets. Gigascience 4:7. https: //doi.org/10.1186/s13742-015-0047-8.

Charlesworth, D., and J. H. Willis. 2009. The genetics of inbreeding depression. Nat. Rev. Genet. 10:783-796. https://doi.org/10.1038/ nrg2664.

Chen, E. Y., C. M. Tan, Y. Kou, Q. Duan, Z. Wang, G. V. Meirelles, N. R. Clark, and A. Ma'ayan. 2013. Enrichr: Interactive and collaborative HTML5 gene list enrichment analysis tool. BMC Bioinformatics 14:128. https://doi.org/10.1186/1471-2105-14-128.

Cohen-Zinder, M., E. Seroussi, D. M. Larkin, J. J. Loor, A. EvertsVan Der Wind, J. H. Lee, J. K. Drackley, M. R. Band, A. G. Hernandez, M. Shani, H. A. Lewin, J. I. Weller, and M. Ron. 2005. Identification of a missense mutation in the bovine $A B C G 2$ gene with a major effect on the QTL on chromosome 6 affecting milk yield and composition in Holstein cattle. Genome Res. 15:936-944. https://doi.org/10.1101/gr.3806705.
Falconer, D. S., and T. F. C. Mackay. 1996. Introduction into Quantitative Genetics. Harlow.

Ferenčaković, M., E. Hamzić, B. Gredler, T. R. Solberg, G. Klemetsdal, I. Curik, and J. Sölkner. 2013a. Estimates of autozygosity derived from runs of homozygosity: Empirical evidence from selected cattle populations. J. Anim. Breed. Genet. 130:286-293. https:// doi.org/10.1111/jbg.12012.

Ferenčaković, M., J. Sölkner, and I. Curik. 2013b. Estimating autozygosity from high-throughput information: Effects of SNP density and genotyping errors. Genet. Sel. Evol. 45:42. https://doi.org/10 .1186/1297-9686-45-42.

Fernández, A., J. Rodrigáñez, M. A. Toro, M. C. Rodríguez, and L. Silió. 2002. Inbreeding effects on the parameters of the growth function in three strains of Iberian pigs. J. Anim. Sci. 80:2267. https://doi.org/10.2527/2002.8092267x.

Fontanesi, L. 2009. Genetic authentication and traceability of food products of animal origin: New developments and perspectives. Ital. J. Anim. Sci. 8(Suppl. 2):9-18. https://doi.org/10.4081/ijas .2009.s2.9.

Fontanesi, L., F. Beretti, V. Riggio, E. Gómez González, S. Dall'Olio, R. Davoli, V. Russo, and B. Portolano. 2009. Copy number variation and missense mutations of the agouti signaling protein (ASIP) gene in goat breeds with different coat colors. Cytogenet. Genome Res. 126:333-347. https://doi.org/10.1159/000268089.

Fontanesi, L., L. Forestier, D. Allain, E. Scotti, F. Beretti, S. DeretzPicoulet, E. Pecchioli, C. Vernesi, T. J. Robinson, J. L. Malaney, V. Russo, and A. Oulmouden. 2010a. Characterization of the rabbit agouti signaling protein (ASIP) gene: Transcripts and phylogenetic analyses and identification of the causative mutation of the nonagouti black coat colour. Genomics 95:166-175. https:// doi.org/10.1016/j.ygeno.2009.11.003.

Fontanesi, L., E. Scotti, and V. Russo. 2010b. Analysis of SNPs in the KIT gene of cattle with different coat colour patterns and perspectives to use these markers for breed traceability and authentication of beef and dairy products. Ital. J. Anim. Sci. 9:e42. https://doi .org/10.4081/ijas.2010.e42.

Fontanesi, L., E. Scotti, and V. Russo. 2012. Haplotype variability in the bovine MITF gene and association with piebaldism in Holstein and Simmental cattle breeds. Anim. Genet. 43:250-256. https:// doi.org/10.1111/j.1365-2052.2011.02242.x.

Fontanesi, L., E. Scotti, A. B. Samorè, A. Bagnato, and V. Russo. 2015. Association of 20 candidate gene markers with milk production and composition traits in sires of Reggiana breed, a local dairy cattle population. Livest. Sci. 176:14-21. https://doi.org/10.1016/ j.livsci.2015.03.022.

Fontanesi, L., M. Tazzoli, V. Russo, and J. Beever. 2010c. Genetic heterogeneity at the bovine KIT gene in cattle breeds carrying different putative alleles at the spotting locus. Anim. Genet. 41:295303. https://doi.org/10.1111/j.1365-2052.2009.02007.x.

Gandini, G., C. Maltecca, F. Pizzi, A. Bagnato, and R. Rizzi. 2007. Comparing local and commercial breeds on functional traits and profitability: The case of Reggiana dairy cattle. J. Dairy Sci. 90:2004-2011. https://doi.org/10.3168/jds.2006-204.

Gibson, J., N. E. Morton, and A. Collins. 2006. Extended tracts of homozygosity in outbred human populations. Hum. Mol. Genet. 15:789-795. https://doi.org/10.1093/hmg/ddi493.

Goyache, F., J. P. Gutiérrez, I. Fernández, E. Gomez, I. Alvarez, J. Díez, and L. J. Royo. 2003. Using pedigree information to monitor genetic variability of endangered populations: The Xalda sheep breed of Asturias as an example. J. Anim. Breed. Genet. 120:95105. https://doi.org/10.1046/j.1439-0388.2003.00378.x.

Granado-Tajada, I., S. T. Rodríguez-Ramilo, A. Legarra, and E. Ugarte. 2020. Inbreeding, effective population size, and coancestry in the Latxa dairy sheep breed. J. Dairy Sci. 103:5215-5226. https: //doi.org/10.3168/jds.2019-17743.

Gurgul, A., T. Szmatoła, P. Topolski, I. Jasielczuk, K. Żukowski, and M. Bugno-Poniewierska. 2016. The use of runs of homozygosity for estimation of recent inbreeding in Holstein cattle. J. Appl. Genet. 57:527-530. https://doi.org/10.1007/s13353-016-0337-6.

Gutiérrez, J. P., J. Altarriba, C. Díaz, R. Quintanilla, J. Cañón, and J. Piedrafita. 2003. Pedigree analysis of eight Spanish beef cattle 
breeds. Genet. Sel. Evol. 35:43-63. https://doi.org/10.1186/1297 -9686-35-1-43.

Gutiérrez, J. P., and F. Goyache. 2005. A note on ENDOG: A computer program for analysing pedigree information. J. Anim. Breed. Genet. 122:172-176. https://doi.org/10.1111/j.1439-0388.2005 $.00512 . x$.

Hill, W. G., and B. S. Weir. 2011. Variation in actual relationship as a consequence of Mendelian sampling and linkage. Genet. Res. 93:47-64. https://doi.org/10.1017/S0016672310000480.

Howard, J. T., J. E. Pryce, C. Baes, and C. Maltecca. 2017. Invited review: Inbreeding in the genomics era: Inbreeding, inbreeding depression, and management of genomic variability. J. Dairy Sci. 100:6009-6024. https://doi.org/10.3168/jds.2017-12787.

Joaquim, L. B., T. C. S. Chud, J. A. P. Marchesi, R. P. Savegnago, M. E. Buzanskas, R. Zanella, M. E. Cantão, J. O. Peixoto, M. C. Ledur, R. Irgang, and D. P. Munari. 2019. Genomic structure of a crossbred Landrace pig population. PLoS One 14:e0212266. https: //doi.org/10.1371/journal.pone.0212266.

Keller, M. C., P. M. Visscher, and M. E. Goddard. 2011. Quantification of inbreeding due to distant ancestors and its detection using dense single nucleotide polymorphism data. Genetics 189:237-249. https://doi.org/10.1534/genetics.111.130922.

Kirin, M., R. McQuillan, C. S. Franklin, H. Campbell, P. M. McKeigue, and J. F. Wilson. 2010. Genomic runs of homozygosity record population history and consanguinity. PLoS One 5:13996. https://doi.org/10.1371/journal.pone.0013996.

Knief, U., B. Kempenaers, and W. Forstmeier. 2017. Meiotic recombination shapes precision of pedigree- and marker-based estimates of inbreeding. Heredity 118:239-248. https://doi.org/10.1038/hdy .2016 .95 .

Kristensen, T. N., and A. C. Sørensen. 2005. Inbreeding - Lessons from animal breeding, evolutionary biology and conservation genetics. Anim. Sci. 80:121-133. https://doi.org/10.1079/ASC41960121.

Lashmar, S. F., C. Visser, E. van Marle-Köster, and F. C. Muchadeyi. 2018. Genomic diversity and autozygosity within the SA Drakensberger beef cattle breed. Livest. Sci. 212:111-119. https://doi.org/ 10.1016/j.livsci.2018.04.006.

Leutenegger, A. L., B. Prum, E. Génin, C. Verny, A. Lemainque, F. Clerget-Darpoux, and E. A. Thompson. 2003. Estimation of the inbreeding coefficient through use of genomic data. Am. J. Hum. Genet. 73:516-523. https://doi.org/10.1086/378207.

Lindholm-Perry, A. K., A. K. Sexten, L. A. Kuehn, T. P. L. Smith, D. A. King, S. D. Shackelford, T. L. Wheeler, C. L. Ferrell, T. G. Jenkins, W. M. Snelling, and H. C. Freetly. 2011. Association, effects and validation of polymorphisms within the NCAPG - LCORL locus located on BTA6 with feed intake, gain, meat and carcass traits in beef cattle. BMC Genet. 12:103. https://doi.org/10.1186/ 1471-2156-12-103.

Maignel, L., D. Boichard, and E. Verrier. 1996. Genetic variability of French dairy breeds estimated from pedigree information. Interbull Bull. 14:49-56.

Makanjuola, B. O., C. Maltecca, F. Miglior, F. S. Schenkel, and C. F. Baes. 2020. Effect of recent and ancient inbreeding on production and fertility traits in Canadian Holsteins. BMC Genomics 21:605. https://doi.org/10.1186/s12864-020-07031-w.

Mancin, E., M. Ablondi, R. Mantovani, G. Pigozzi, A. Sabbioni, and C. Sartori. 2020. Genetic variability in the Italian Heavy Draught Horse from pedigree data and genomic information. Animals (Basel) 10:1310. https://doi.org/10.3390/ani10081310.

Marras, G., G. Gaspa, S. Sorbolini, C. Dimauro, P. Ajmone-Marsan, A. Valentini, J. L. Williams, and N. P. P. MacCiotta. 2015. Analysis of runs of homozygosity and their relationship with inbreeding in five cattle breeds farmed in Italy. Anim. Genet. 46:110-121. https://doi.org/10.1111/age.12259.

Mastrangelo, S., E. Ciani, P. Ajmone Marsan, A. Bagnato, L. Battaglini, R. Bozzi, A. Carta, G. Catillo, M. Cassandro, S. Casu, R. Ciampolini, P. Crepaldi, M. D'Andrea, R. Di Gerlando, L. Fontanesi, M. Longeri, N. P. Macciotta, R. Mantovani, D. Marletta, D. Matassino, M. Mele, G. Pagnacco, C. Pieramati, B. Portolano, F. M. Sarti, M. Tolone, and F. Pilla. 2018a. Conservation status and historical relatedness of Italian cattle breeds. Genet. Sel. Evol. 50:35. https://doi.org/10.1186/s12711-018-0406-x.

Mastrangelo, S., M. T. Sardina, M. Tolone, R. Di Gerlando, A. M. Sutera, L. Fontanesi, and B. Portolano. 2018b. Genome-wide identification of runs of homozygosity islands and associated genes in local dairy cattle breeds. Animal 12:2480-2488. https://doi.org/10 $.1017 /$ S1751731118000629.

Mastrangelo, S., M. Tolone, R. Di Gerlando, L. Fontanesi, M. T. Sardina, and B. Portolano. 2016. Genomic inbreeding estimation in small populations: Evaluation of runs of homozygosity in three local dairy cattle breeds. Animal 10:746-754. https://doi.org/10 $.1017 /$ S1751731115002943.

McQuillan, R., A. L. Leutenegger, R. Abdel-Rahman, C. S. Franklin, M. Pericic, L. Barac-Lauc, N. Smolej-Narancic, B. Janicijevic, O. Polasek, A. Tenesa, A. K. MacLeod, S. M. Farrington, P. Rudan, C. Hayward, V. Vitart, I. Rudan, S. H. Wild, M. G. Dunlop, A. F. Wright, H. Campbell, and J. F. Wilson. 2008. Runs of homozygosity in European populations. Am. J. Hum. Genet. 83:359-372. https://doi.org/10.1016/j.ajhg.2008.08.007.

Meuwissen, T. H. E. 1991. Reduction of selection differentials in finite populations with a nested full-half sib family structure. Biometrics 47:195-203. https://doi.org/10.2307/2532506.

Meuwissen, T. H. E., and Z. Luo. 1992. Computing inbreeding coefficients in large populations. Genet. Sel. Evol. 24:305. https://doi .org/10.1186/1297-9686-24-4-305.

Meyermans, R., W. Gorssen, N. Buys, and S. Janssens. 2020. How to study runs of homozygosity using PLINK? A guide for analyzing medium density SNP data in livestock and pet species. BMC Genomics 21:94. https://doi.org/10.1186/s12864-020-6463-x.

Nkrumah, J. D., E. L. Sherman, C. Li, E. Marques, D. H. Crews Jr., R. Bartusiak, B. Murdoch, Z. Wang, J. A. Basarab, and S. S. Moore. 2007. Primary genome scan to identify putative quantitative trait loci for feedlot growth rate, feed intake, and feed efficiency of beef cattle. J. Anim. Sci. 85:3170-3181. https://doi.org/ $10.2527 /$ jas.2007-0234

Norris, B. J., and V. A. Whan. 2008. A gene duplication affecting expression of the ovine $A S I P$ gene is responsible for white and black sheep. Genome Res. 18:1282-1293. https://doi.org/10.1101/ gr.072090.107.

Oliehoek, P. A., and P. Bijma. 2009. Effects of pedigree errors on the efficiency of conservation decisions. Genet. Sel. Evol. 41:9. https:/ /doi.org/10.1186/1297-9686-41-9.

Peripolli, E., J. Metzger, M. V. A. de Lemos, N. B. Stafuzza, S. Kluska, B. F. Olivieri, F. L. B. Feitosa, M. P. Berton, F. B. Lopes, D. P. Munari, R. B. Lôbo, C. D. U. Magnabosco, F. Di Croce, J. Osterstock, S. Denise, A. S. C. Pereira, and F. Baldi. 2018a. Autozygosity islands and $\mathrm{ROH}$ patterns in Nellore lineages: Evidence of selection for functionally important traits. BMC Genomics 19:680. https://doi.org/10.1186/s12864-018-5060-8.

Peripolli, E., N. B. Stafuzza, D. P. Munari, A. L. F. Lima, R. Irgang, M. A. Machado, J. C. C. Panetto, R. V. Ventura, F. Baldi, and M. V. G. B. da Silva. 2018b. Assessment of runs of homozygosity islands and estimates of genomic inbreeding in Gyr (Bos indicus) dairy cattle. BMC Genomics 19:34. https://doi.org/10.1186/ s12864-017-4365-3.

Pryce, J. E., M. Haile-Mariam, M. E. Goddard, and B. J. Hayes. 2014. Identification of genomic regions associated with inbreeding depression in Holstein and Jersey dairy cattle. Genet. Sel. Evol. 46:71. https://doi.org/10.1186/s12711-014-0071-7.

Pryce, J. E., B. J. Hayes, S. Bolormaa, and M. E. Goddard. 2011. Polymorphic regions affecting human height also control stature in cattle. Genetics 187:981-984. https://doi.org/10.1534/genetics .110 .123943 .

Purfield, D. C., D. P. Berry, S. McParland, and D. G. Bradley. 2012. Runs of homozygosity and population history in cattle. BMC Genet. 13:70. https://doi.org/10.1186/1471-2156-13-70.

Purfield, D. C., S. McParland, E. Wall, and D. P. Berry. 2017. The distribution of runs of homozygosity and selection signatures in six commercial meat sheep breeds. PLoS One 12:e0176780. https:// doi.org/10.1371/journal.pone.0176780. 
Randhawa, I. A. S., M. S. Khatkar, P. C. Thomson, and H. W. Raadsma. 2015. Composite selection signals for complex traits exemplified through bovine stature using multibreed cohorts of European and African Bos taurus. G3 (Bethesda) 5:1391-1401. https://doi .org/10.1534/g3.115.017772.

Reverter, A., L. R. Porto-Neto, M. R. S. Fortes, R. McCulloch, R. E. Lyons, S. Moore, D. Nicol, J. Henshall, and S. A. Lehnert. 2016. Genomic analyses of tropical beef cattle fertility based on genotyping pools of Brahman cows with unknown pedigree. J. Anim. Sci. 94:4096-4108. https://doi.org/10.2527/jas.2016-0675.

Rodríguez-Ramilo, S. T., J. M. Elsen, and A. Legarra. 2019. Inbreeding and effective population size in French dairy sheep: Comparison between genomic and pedigree estimates. J. Dairy Sci. 102:4227-4237. https://doi.org/10.3168/jds.2018-15405.

Ron, M., Y. Blanc, M. Band, E. Ezra, and J. I. Weller. 1996. Misidentification rate in the Israeli dairy cattle population and its implications for genetic improvement. J. Dairy Sci. 79:676-681. https:// doi.org/10.3168/jds.S0022-0302(96)76413-5.

Russo, V., L. Fontanesi, M. Dolezal, E. Lipkin, E. Scotti, P. Zambonelli, S. Dall'Olio, D. Bigi, R. Davoli, F. Canavesi, I. Medugorac, M. Föster, J. Sölkner, F. Schiavini, A. Bagnato, and M. Soller. 2012. A whole genome scan for QTL affecting milk protein percentage in Italian Holstein cattle, applying selective milk DNA pooling and multiple marker mapping in a daughter design. Anim. Genet. 43:72-86. https://doi.org/10.1111/j.1365-2052.2012.02353.x.

Russo, V., L. Fontanesi, E. Scotti, M. Tazzoli, S. Dall'Olio, and R. Davoli. 2007. Analysis of melanocortin 1 receptor (MC1R) gene polymorphisms in some cattle breeds: Their usefulness and application for breed traceability and authentication of Parmigiano Reggiano cheese. Ital. J. Anim. Sci. 6:257-272. https://doi.org/10 .4081/ijas.2007.257.

Sanders, K., J. Bennewitz, and E. Kalm. 2006. Wrong and missing sire information affects genetic gain in the Angeln dairy cattle population. J. Dairy Sci. 89:315-321. https://doi.org/10.3168/jds.S0022 -0302(06)72096-3.

Schiavo, G., S. Bovo, F. Bertolini, S. Dall'Olio, L. Nanni Costa, S. Tinarelli, M. Gallo, and L. Fontanesi. 2020a. Runs of homozygosity islands in Italian cosmopolitan and autochthonous pig breeds identify selection signatures in the porcine genome. Livest. Sci. 240:104219. https://doi.org/10.1016/j.livsci.2020.104219.

Schiavo, G., S. Bovo, F. Bertolini, S. Tinarelli, S. Dall'Olio, L.N. Costa, M. Gallo, and L. Fontanesi. 2020b. Comparative evaluation of genomic inbreeding parameters in seven commercial and autochthonous pig breeds. Animal 14:910-920. https://doi.org/10.1017/ s175173111900332x.

Schiavo, G., S. Bovo, M. Muñoz, A. Ribani, E. Alves, J. P. Araújo, R. Bozzi, M. Čandek-Potokar, R. Charneca, A. I. Fernandez, M. Gallo, F. García, D. Karolyi, G. Kušec, J. M. Martins, M. J. Mercat, Y. Núñez, R. Quintanilla, V. Radović, V. Razmaite, J. Riquet, R. Savić, G. Usai, V. J. Utzeri, C. Zimmer, C. Ovilo, and L. Fontanesi. 2021a. Runs of homozygosity provide a genome landscape picture of inbreeding and genetic history of European autochthonous and commercial pig breeds. Anim. Genet. 52:155-170. https: //doi.org/10.1111/age.13045.

Schiavo, G., S. Bovo, A. Ribani, G. Moscatelli, M. Bonacini, M. Prandi, E. Mancin, R. Mantovani, S. Dall'Olio, and L. Fontanesi. 2021b. Supplementary tables for "Comparative inbreeding analyses in cattle." https://doi.org/10.5281/zenodo.5532620.

Setoguchi, K., M. Furuta, T. Hirano, T. Nagao, T. Watanabe, Y. Sugimoto, and A. Takasuga. 2009. Cross-breed comparisons identified a critical 591-kb region for bovine carcass weight QTL (CW-2) on chromosome 6 and the Ile-442-Met substitution in NCAPG as a positional candidate. BMC Genet. 10:43. https://doi.org/10.1186/ 1471-2156-10-43.

Signer-Hasler, H., A. Burren, M. Neuditschko, M. Frischknecht, D. Garrick, C. Stricker, B. Gredler, B. Bapst, and C. Flury. 2017. Population structure and genomic inbreeding in nine Swiss dairy cattle populations. Genet. Sel. Evol. 49:83. https://doi.org/10 .1186/s12711-017-0358-6.

Slate, J., P. David, K. G. Dodds, B. A. Veenvliet, B. C. Glass, T. E. Broad, and J. C. McEwan. 2004. Understanding the relationship between the inbreeding coefficient and multilocus heterozygosity: Theoretical expectations and empirical data. Heredity 93:255-265. https://doi.org/10.1038/sj.hdy.6800485.

Smith, L. A., B. G. Cassell, and R. E. Pearson. 1998. The effects of inbreeding on the lifetime performance of dairy cattle. J. Dairy Sci. 81:2729-2737. https://doi.org/10.3168/jds.S0022-0302(98)75830 -8 .

Sumreddee, P., S. Toghiani, E. H. Hay, A. Roberts, S. E. Agrrey, and R. Rekaya. 2019. Inbreeding depression in line 1 Hereford cattle population using pedigree and genomic information. J. Anim. Sci. 97:1-18. https://doi.org/10.1093/jas/sky385.

Szmatoła, T., A. Gurgul, K. Ropka-Molik, I. Jasielczuk, T. Zabek, and M. Bugno-Poniewierska. 2016. Characteristics of runs of homozygosity in selected cattle breeds maintained in Poland. Livest. Sci. 188:72-80. https://doi.org/10.1016/j.livsci.2016.04.006.

Trigo, B. B., A. T. H. Utsunomiya, A. A. A. D. Fortunato, M. Milanesi, R. B. P. Torrecilha, H. Lamb, L. Nguyen, E. M. Ross, B. Hayes, R. C. M. Padula, T. S. Sussai, L. B. Zavarez, R. S. Cipriano, M. M. T. Caminhas, F. L. Lopes, C. Pelle, T. Leeb, D. Bannasch, D. Bickhart, T. P. L. Smith, T. S. Sonstegard, J. F. Garcia, and Y. T. Utsunomiya. 2021. Variants at the ASIP locus contribute to coat color darkening in Nellore cattle. Genet. Sel. Evol. 53:40. https:// doi.org/10.1186/s12711-021-00633-2.

VanRaden, P. M. 1992. Accounting for inbreeding and crossbreeding in genetic evaluation of large populations. J. Dairy Sci. 75:3136-3144. https://doi.org/10.3168/jds.S0022-0302(92)78077-1.

VanRaden, P. M. 2007. Genomic measures of relationship and inbreeding. Interbull Bull. 37:33-36.

VanRaden, P. M. 2008. Efficient methods to compute genomic predictions. J. Dairy Sci. 91:4414-4423. https://doi.org/10.3168/jds 2007-0980.

VanRaden, P. M., K. M. Olson, D. J. Null, and J. L. Hutchison. 2011. Harmful recessive effects on fertility detected by absence of homozygous haplotypes. J. Dairy Sci. 94:6153-6161. https://doi.org/10 $.3168 /$ jds.2011-4624.

Visscher, P. M., J. A. Woolliams, D. Smith, and J. L. Williams. 2002. Estimation of pedigree errors in the UK dairy population using microsatellite markers and the impact on selection. J. Dairy Sci. 85:2368-2375. https://doi.org/10.3168/jds.S0022-0302(02)74317 -8 .

Wang, J. 2016. Pedigrees or markers: Which are better in estimating relatedness and inbreeding coefficient? Theor. Popul. Biol. 107:413. https://doi.org/10.1016/j.tpb.2015.08.006.

Weller, J. I., E. Feldmesser, M. Golik, I. Tager-Cohen, R. Domochovsky, O. Alus, E. Ezra, and M. Ron. 2004. Factors affecting incorrect paternity assignment in the Israeli Holstein population. J. Dairy Sci. 87:2627-2640. https://doi.org/10.3168/jds.S0022 -0302(04)73389-5.

Wright, D. 1922. Coefficients of inbreeding and relationship. Am. Nat. 56:330-338. https://doi.org/10.1086/279872.

Yang, J., S. H. Lee, M. E. Goddard, and P. M. Visscher. 2011. GCTA: A tool for genome-wide complex trait analysis. Am. J. Hum. Genet. 88:76-82. https://doi.org/10.1016/j.ajhg.2010.11.011.

Zhang, Q., M. P. L. Calus, B. Guldbrandtsen, M. S. Lund, and G. Sahana. 2015. Estimation of inbreeding using pedigree, 50k SNP chip genotypes and full sequence data in three cattle breeds. BMC Genet. 16:88. https://doi.org/10.1186/s12863-015-0227-7.

Zhang, Z., Q. Zhang, Q. Xiao, H. Sun, H. Gao, Y. Yang, J. Chen, Z. Li, M. Xue, P. Ma, H. Yang, N. Xu, Q. Wang, and Y. Pan. 2018. Distribution of runs of homozygosity in Chinese and Western pig breeds evaluated by reduced-representation sequencing data. Anim. Genet. 49:579-591. https://doi.org/10.1111/age.12730.

\section{ORCIDS}

Giuseppina Schiavo @ https://orcid.org/0000-0002-3497-1337 Samuele Bovo @ https://orcid.org/0000-0002-5712-8211 